\title{
Physical model of wave-induced seabed response around trenched pipeline in sandy seabed
}

\author{
Yanyan Zhai ${ }^{1,2}$, Rui He ${ }^{1,2}$, Jialin Zhao ${ }^{1,2}$, Jisheng Zhang ${ }^{1,2, *}$, Dong-Sheng Jeng ${ }^{1,2,3}$, Ling Li ${ }^{4}$ \\ ${ }^{1}$ State Key Laboratory of Hydrology-Water Resources and Hydraulic Engineering, Hohai \\ University, Nanjing 210098, China \\ ${ }^{2}$ College of Harbor, Coastal and Offshore Engineering, Hohai University, Nanjing 210098, China \\ ${ }^{3}$ School of Engineering \& Built Environment, Griffith University Gold Coast Campus, \\ Queensland 4222, Australia \\ ${ }^{4}$ College of Water Conservancy and Hydropower Engineering, Hohai University, Nanjing 210098, \\ China \\ *Corresponding author: jszhang@hhu.edu.cn
}

\begin{abstract}
The phenomenon of wave-seabed-pipeline interactions is one of the primary concerns of coastal engineers and researchers, as it could greatly affect the seabed instability and pipeline safety. Numerous researchers have expended great effort in studying wave-seabed-pipeline interactions in the past. However, the majority of them focussed on the wave-induced response around a submarine pipeline, in buried conditions, by numerical models and laboratory experiments. Unlike the previous studies, a series of regular wave experiments and numerical model analyses were conducted to investigate the wave-induced pore pressure in the sandy seabed, around a pipeline with different backfilled depths. The model pipeline with three diameters $(D=6 \mathrm{~cm}, 8 \mathrm{~cm}$, and 10 $\mathrm{cm}$ ) is buried in three sizes of sand, $d_{50}=0.15 \mathrm{~mm}, d_{50}=0.3 \mathrm{~mm}$, and $d_{50}=0.5 \mathrm{~mm}$, with different backfilled depths. The results show that the pore pressure amplitude in the seabed is a minimum with a backfilled depth $D$, and a maximum with full backfill or a backfilled depth of zero. The pore-pressure amplitude increases as the backfill sand median diameter increases. The effects of the pipeline diameter on pore-water pressure are also analysed and discussed.
\end{abstract}

Keywords: Wave-seabed-pipeline interactions; sandy seabed; backfilled depth; backfill soil type; pipeline diameter.

\section{Introduction}

Submarine pipelines play an extremely important role in offshore engineering for the transportation of offshore oil and gas. One of the critical problems in the design of a pipeline, that is laid on or partly buried in the porous seabed, is to assess whether the pipeline will remain stable with the strong action of ocean waves. Clearly, the wave-induced seabed interaction around the pipeline is of particular importance in the design of offshore pipeline installations, and has attracted considerable attention among coastal and geotechnical engineers. In the past years, numerous offshore pipelines have been reported damaged from wave-induced seabed instability [1-4], as opposed to construction or material breakdowns. When a pipeline is placed in a trench with different backfilled depths, it could significantly disturb the wave motion and wave pressure around the pipeline, and consequently lead to changes in the effective stress in the seabed. Therefore, the evaluation of the wave-induced seabed response is of particular importance when designing protection of offshore pipelines.

Because of its practical importance, and potential engineering applications, extensive investigations on the interaction between waves, seabed, and pipelines have been conducted in recent years, using both theoretical and experimental approaches [5, 6]. However, understanding the results of studies on wave-seabed-trenched pipelines, with different backfilled depths, remains incomplete. For example, MacPherson [7] studied the wave-induced pore pressure in a permeable seabed around a pipeline, and indicated that the seepage force should be considered. Cheng and Liu [8] used a boundary integral equation method to investigate the effects of wave and seabed parameters on the uplift seepage force and pore pressure around a pipeline, that was buried in a rectangular region with impermeable walls. There were a number of numerical analyses considering the effects of a cover layer with full backfilled conditions on the wave-induced seabed 
dynamic response around a buried pipeline [9-12]. However, these models may not be able to predict the seabed response in the neighbourhood of a pipeline when a wave is propagating over a partially backfilled pipeline, as opposed to fully backfilled. More recently, Zhao et al. [13] and Lin et al. [14] developed numerical models to investigate wave-induced soil responses around a buried pipeline, that was partially backfilled, and predicted the stability of a submarine pipeline. Their results showed that the pipeline backfilled up to a certain depth is better protected against waveinduced liquefaction.

In addition to the aforementioned theoretical methods mentioned above, some laboratory experiments have been conducted to investigate wave-induced soil dynamic responses, and the stability of offshore pipelines. Among these, Pan and Wang [15] carried out a series of large-scale laboratory experiments to study wave-induced pore pressures around shallowly embedded pipelines. Higher pore pressures were recorded at the top, and lower pore pressures at the bottom of a pipeline, for a sandy seabed. Sumer et al. $[16,17]$ conducted a series of physical experiments to investigate the stability of pipelines on a liquefied sandy seabed, and the onset of scour below the pipeline in currents/waves. By analysing the pore-water pressures measured upstream and downstream of a partially buried pipeline, they reported that the excessive seepage flow and the resulting piping were two primary factors that caused the onset of scour below the pipeline. Sumer et al. [18] further extended the physical experiments to investigate the dynamic response around a pipeline buried in soil, and exposed to a progressive wave, by measuring pore pressures. The presence of the pipeline had no major influence on the build-up of pore pressure at the top of the pipe. The results further indicated that liquefaction initially occurred in the very top layer, and developed downwards, but was different in the vicinity of the pipe. Recently, Zhou et al. [19] experimentally studied the combined effects of waves and currents on the characteristics of soil responses around a marine pipeline. The results showed that the current intensifies the erosion process in all types of soils, and pore pressures in sandy soil decrease marginally over time. Yang et al. [20-22] presented results from a series of laboratory experimental models that studied the major safety issues of subsea pipelines induced by seabed scouring. A rubber plate was placed between the submarine pipeline and the bed, while a rigid spoiler was attached to the top of the pipe. The experiments showed that the rigid spoiler could increase the scour depth, thus greatly speeding up self-burying. In addition, they found that there existed a critical length of rubber plate, greater than which there was no scour around the pipeline and the pipeline was protected. If the rubber plate was shorter than the critical length, scour around the pipeline was significantly increased and self-burial of the pipe was accelerated. Recently, Fredsøe [23] reviewed the cause of pipeline-seabed interaction and the resulting consequences for pipeline stability in a natural environment.

The aforementioned studies focused on the wave-induced seabed response around a pipeline that is either fully buried, or resting on the seabed in different types of soil. However, in engineering practice, pipelines are occasionally placed in a trench that is partially backfilled with soil excavated from the seabed during trenching, or coarser materials, to reduce the possibility of instability/liquefaction. To date, only a few theoretical studies regarding the effects of partial backfill on the wave-induced seabed response around a buried pipeline are available in the literature, therefore, the actual mechanisms behind this marine process may not be fully captured or explained. Moreover, there is no physical modelling for the effects of a backfill layer on the dynamic soil response surrounding a trenched pipeline. Therefore, it is important to conduct such an experiment to properly and accurately predict wave-induced soil response around a pipeline, that is partially backfilled, in a porous seabed. The primary aim of this study is to present results from an experimental study of soil behaviour around a trenched pipeline, with different backfill depths in various types of soils, subject to regular wave action. To the best of the authors knowledge, the present study is the first set of wave experiments regarding a trench layer with a partially buried pipeline. At the same time, a numerical model is used to investigate the distribution of wave-induced pore-water pressure for different seabed conditions.

\section{Experiment model}

\subsection{Experimental set-up}


The experiments were conducted in a wave flume, $1.0 \mathrm{~m}$ wide, $1.3 \mathrm{~m}$ deep, and $50 \mathrm{~m}$ long. The experiment was performed at a 1:30 geometric scale, and at a $1 g$ condition ( $g$ is the gravational acceleration). Hettler [24] pointed out that, at $1 g$, the soil in a field test can be used in model experiments without particle size scaling, although the geotechnical engineers argued about the stress level within the seabed. Figure 1 shows the detailed setup of the experiment. The bottom of the flume was elevated $0.25 \mathrm{~m}$ by constructing plywood floors on both sides of the sediment basin. Two plywood ramps, with a 1:10 slope, were built at the end of the false floors to ensure smooth transformation of the waves before entering the measuring section. The flume comprised a pistontype wave generator and two porous, sloped wave absorbers at either end of the flume to minimise wave reflections. The wave maker could generate regular waves with periods $0.6-2.5 \mathrm{~s}$, and wave heights up to $0.2 \mathrm{~m}$. Four wave-height gauges were positioned along the central axis of the flume to measure the variation of wave height at the test section. The specific locations are depicted in Figure 1. The water level on top of the mudline (i.e., water depth) in all tests was maintained at $0.40 \mathrm{~m}$.

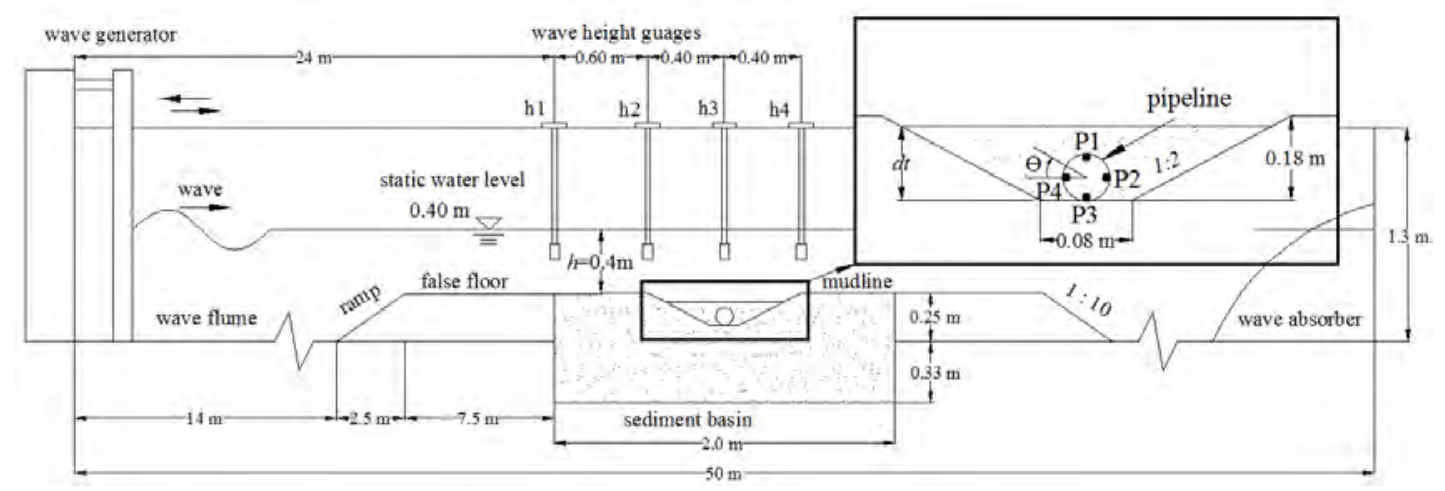

Figure 1. Schematic of wave flume

The $2.0 \mathrm{~m}$ long, $0.58 \mathrm{~m}$ deep, and $1.0 \mathrm{~m}$ wide sediment basin was in the middle section of the wave flume. Sandy sediment was used for the laboratory experiments, and its properties are presented in Table 1, where $\gamma_{s}$ is the unit weight of soil, and $\gamma_{w}$ is the unit weight of pure water. The shear wave velocity method is used to measure shear modulus $G$, and the Poisson's ratio $v$ is obtained from a tri-axial test. The Young's modulus $(E)$ is calculated from the measured shear modulus and Poisson's ratio. The permeability coefficient is measured by the constant head permeability test.

To form the sandy bed, sand and water are mixed thoroughly, using an ordinary mixer that can release the air from the sand, into a thick slurry in a large plastic box. The thick slurry is then slowly injected into the sand tank by a suction pump, and is allowed to consolidate for several hours. This process is repeated until the mudline reaches the top rim of the sand tank. Water is then slowly poured into the flume to reach the designated water depth $(h=0.4 \mathrm{~m})$. Fluid loading from the still water is imposed on the sandy seabed for 3 days, until the subsidence of the mudline is negligible, that is, the variation of the void ratio is insignificant. After the completed process, artificial actions will not affect the degree of saturation of the sandy bed. A trench was formed using an inverted trapezoidal iron block placed in the sand pit, and the block was removed once the trench walls stabilised with the profile. The trench was $0.80 \mathrm{~m}$ long on top, $0.08 \mathrm{~m}$ long on the bottom, $1.0 \mathrm{~m}$ wide, and $0.18 \mathrm{~m}$ deep. A PMMA (poly-methyl-methacrylate) pipe was used in the experiment to model the submarine pipeline. The length of the pipes was $1.0 \mathrm{~m}$, and the external diameters used were $6 \mathrm{~cm}, 8 \mathrm{~cm}$, and $10 \mathrm{~cm}$. As shown in Figure 1, the pipeline was positioned at the centre of the trench bottom, and four pore-pressure transducers were equally spaced around the circumference of the centre section the pipeline. The trenched pipeline was buried in three sizes of sand, $d_{50}=0.15 \mathrm{~mm}, 0.3 \mathrm{~mm}$, and $0.5 \mathrm{~mm}$, with different backfilled depths. During the experiments, only the median diameter of the backfill material was changed, from 0.15 $\mathrm{mm}$, through $0.3 \mathrm{~mm}$ to $0.5 \mathrm{~mm}$, but the soil was permanently $d_{50}=0.15 \mathrm{~mm}$. In addition, the denseness of the backfilled soil $\left(d_{50}=0.15 \mathrm{~mm}\right)$ was the same over the entire soil domain $\left(d_{50}=\right.$ 
$0.15 \mathrm{~mm}$ ), as the operational processes of both were controlled with the same standard. However, the denseness of the other backfilled materials, $d_{50}=0.30 \mathrm{~mm}$ and $d_{50}=0.50 \mathrm{~mm}$, differed from the entire soil domain $\left(d_{50}=0.15 \mathrm{~mm}\right)$. The pore pressures on the seabed and the wave heights were measured simultaneously in the experiment. Both sides of the pipeline were fixed to prevent horizontal movement. In addition, the pipeline was allowed to move in the vertical direction. Therefore, the model pipeline was placed with a single degree of freedom as linear vertical motion.

Table 1. Properties of sandy sediment

\begin{tabular}{|c|c|c|c|c|}
\hline Parameter & Symbol & \multicolumn{3}{|c|}{ Value } \\
\hline Mean grain size & $d_{50}(\mathrm{~mm})$ & 0.15 & 0.30 & 0.50 \\
\hline Maximum void ratio & $e_{\max }$ & 0.871 & 0.920 & 0.960 \\
\hline Minimum void ratio & $e_{\min }$ & 0.411 & 0.514 & 0.523 \\
\hline Void ratio & $e$ & 0.584 & 0.694 & 0.749 \\
\hline Porosity & $n$ & 0.369 & 0.410 & 0.428 \\
\hline Relative density & $D_{r}=\frac{e_{\max }-e}{e_{\max }-e_{\min }}$ & 0.624 & 0.557 & 0.518 \\
\hline $\begin{array}{l}\text { Specific gravity of } \\
\text { sediment grain }\end{array}$ & $G_{s}=\gamma_{s} / \gamma_{w}$ & 2.68 & 2.67 & 2.65 \\
\hline Permeability & $k(m / s)$ & $3.57 \times 10^{-5}$ & $2.68 \times 10^{-4}$ & $3.91 \times 10^{-3}$ \\
\hline Poisson's ratio & $v$ & 0.30 & 0.32 & 0.35 \\
\hline Elasticity modulus & $\begin{array}{c}E=\frac{G(1+v)}{2} \\
\left(\mathrm{MN} / \mathrm{m}^{2}\right)\end{array}$ & 53.82 & 50.82 & 47.45 \\
\hline Shear modulus & $G_{-}(\mathrm{MPa})$ & 8.28 & 7.70 & 7.03 \\
\hline
\end{tabular}

\subsection{Experimental conditions and procedure}

The experimental conditions are summarised in Table 2. The duration of data collection in each test was $120 \mathrm{~s}$. According to the diagram of 'the range of suitability of various wave theories' proposed by Lé Mehauté [25], wave conditions in this study fall primarily in one wave-theory zone (Stokes' $3^{r d}$ order) (Figure 2) [16, 25, 26]. In the figure, $H$ is the wave height, $T$ is the wave period, $d$ is the water depth, and $g$ is the gravitational acceleration.

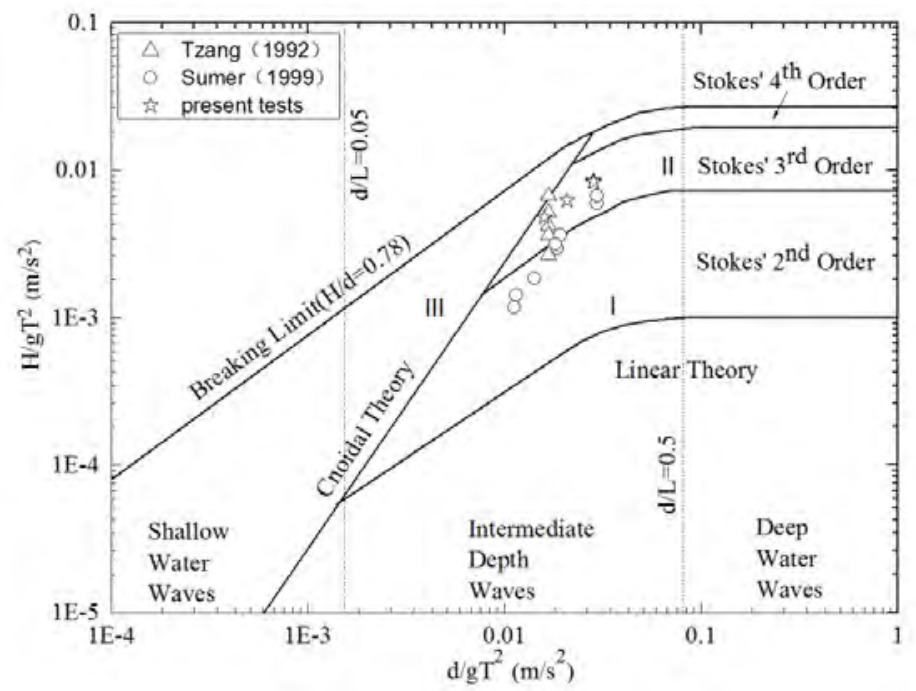

Figure 2. Range of suitability of various wave theories, and comparison of wave conditions between this study and similar experiments of Tzang (1992) and Sumer et al. (1999)The tests were 
conducted for three types of backfill soil, six backfilled depths, and three pipeline diameters under a range of wave conditions. The experimental procedure was as follows.

(1) To install the pore-pressure transducers in the pipeline, four small holes are drilled in the pipeline. The pore-pressure transducers are then installed through these holes, and fixed in place with waterproof tape. The measuring surface of the pore-pressure transducers are flush with the surface of the pipeline to ensure that the measuring sites of the pore pressures are in the vicinity of the pipeline. As the pore-pressure transducers are all equipped with sand filters, they must be installed in water for 24 hours to exhaust all air from them. We judge whether all air in the pore-pressure transducers are exhausted through measuring the hydrostatic pressure. If the measured data is in accordance with the theoretical value, there is no air in the transducers.

(2) The test soils are first mixed with water and then poured into the soil basin filled with water. After that, an inverted trapezoidal iron block is placed at the proper position in the sand tank. Finally, the seabed is trimmed with a scraper, and the soil is left to consolidate for $3 \mathrm{~d}$.

(3) Remove the iron block and place the pipe in the bottom of the trench.

(4) Backfill the trench with the selected backfill material to a certain depth, and let the backfill soil consolidate for $3 \mathrm{~d}$. Then fill the flume with water slowly to the designed water level.

(5) Switch on the wave generator, and sample water surface elevation and pore pressure continuously.

(6) Switch off the wave generator and empty the water in the flume.

(7) After the measurement, repeat steps (2)-(6), keeping the shape of the trench layer, until the trench is fully backfilled.

(8) Empty the sand pit and prepare for the test of the next backfill soil.

Table 2. Experimental conditions

\begin{tabular}{|c|c|c|c|}
\hline \multirow[b]{2}{*}{ Case no. } & \multicolumn{2}{|c|}{ Wave condition } & \multirow{2}{*}{$\begin{array}{c}\text { Backfilled } \\
\text { depth } \\
d_{t} / D\end{array}$} \\
\hline & $\begin{array}{c}\text { Wave height } \\
\quad H(\mathrm{~cm})\end{array}$ & $\begin{array}{c}\text { Wave period } \\
T(s)\end{array}$ & \\
\hline 1 & 10 & 1.2 & 0 \\
\hline 2 & 10 & 1.2 & $1 / 2$ \\
\hline 3 & 10 & 1.2 & 1 \\
\hline 4 & 10 & 1.2 & $3 / 2$ \\
\hline 5 & 10 & 1.2 & 2 \\
\hline 6 & 10 & 1.2 & $9 / 4$ \\
\hline 7 & 10 & 1.4 & 0 \\
\hline 8 & 10 & 1.4 & $1 / 2$ \\
\hline 9 & 10 & 1.4 & 1 \\
\hline 10 & 10 & 1.4 & $3 / 2$ \\
\hline 11 & 10 & 1.4 & 2 \\
\hline 12 & 10 & 1.4 & $9 / 4$ \\
\hline 13 & 10 & 1.6 & 0 \\
\hline 14 & 10 & 1.6 & $1 / 2$ \\
\hline 15 & 10 & 1.6 & 1 \\
\hline 16 & 10 & 1.6 & $3 / 2$ \\
\hline 17 & 10 & 1.6 & 2 \\
\hline 18 & 10 & 1.6 & $9 / 4$ \\
\hline 19 & 12 & 1.2 & 0 \\
\hline 20 & 12 & 1.2 & $1 / 2$ \\
\hline 21 & 12 & 1.2 & 1 \\
\hline 22 & 12 & 1.2 & $3 / 2$ \\
\hline 23 & 12 & 1.2 & 2 \\
\hline 24 & 12 & 1.2 & $9 / 4$ \\
\hline
\end{tabular}

\section{Numerical model}


In this study, the wave-soil-structure interaction (WSSI) model of Zhang et al. [27] is applied to simulate the complex wave-seabed-pipeline interactions, assuming that deformations of the porous seabed are negligible, and have no impact on the wave transformation above the seabed. The wave model COBRAS [28], based on the volume-averaged Reynolds-averaged Navier-Stokes (VARANS) equations, is used to predict the wave pressure and effective stress on the solid-liquid interface, and the flow of the continuous water and permeable material. The wave pressure along the seabed surface is extracted from the wave model, and will be imposed as a boundary condition at the seabed surface of the seabed model. In the WSSI model, an internal wave-maker, developed by Lin and Liu [28], is adopted for wave generation. The damping zones are located on two vertical boundaries, at a distance from the concerned region, and the numerical set-up is shown in Figure 3.

In the WSSI model, a seabed model based on Biot's poro-elastic theory [29] is adopted to simulate pore pressure, soil displacement, and effective stress of the seabed. Biot's equation [29] was used to govern the behaviour of the compressible pore fluid flowing within an elastic porous medium. Therefore, Biot's equation is applied in the seabed model to describe the mechanical behaviour of a uniform and isotropic porous seabed. At the seabed surface, the vertical effective normal stress is assumed to disappear, and the pore pressure and effective stress are equal to the wave pressure and effective stress obtained from wave model, respectively. The seabed bottom with finite thickness is treated as impermeable and rigid, and zero displacement and no vertical flow occur at this boundary. Zero displacement and zero-gradient of pore pressure are adopted on the two vertical sides at a distance from the concerned region. The boundary condition of the pipeline is assumed to be a rigid impermeable material, and no fluid flows through the pipeline surface. Details of the boundary condition are described in the following seabed model.

The Biot's equation applied in the seabed model is written as:

$$
\nabla^{2} \Delta u-\frac{\gamma_{w} n \beta}{k} \frac{\partial \Delta u}{\partial t}=\frac{\gamma_{w}}{k} \frac{\partial}{\partial t}\left(\frac{\partial u_{s}}{\partial x}+\frac{\partial w_{s}}{\partial y}\right),
$$

where $\Delta \mathrm{u}$ is the wave-induced oscillatory pore pressure, $k$ is the permeability in different directions and is taken as the same value in all directions in this study, $n$ is the soil porosity, $\gamma_{w}$ is the unit weight of pore water, $u_{\mathrm{s}}$ and $w_{\mathrm{s}}$ are the soil displacements in the $x$ - and $y$-directions, respectively, and the compressibility of pore fluid, $\beta$, is given by [30]:

$$
\beta=\frac{1}{K_{f}}+\frac{1-S_{r}}{p_{w 0}}
$$

where $K_{f}$ is the true modulus of elasticity of pure water (taken as $2 \times 10^{9} \mathrm{~N} / \mathrm{m}^{2}$ ), $p_{w 0}$ is the absolute water pressure, and $S_{r}$ is the degree of soil saturation [33].

The force equilibrium equations are:

$$
\begin{aligned}
& \frac{\partial \sigma_{x x}^{\prime}}{\partial x}+\frac{\partial \tau_{x y}}{\partial y}=\frac{\partial \Delta u}{\partial x}, \\
& \frac{\partial \tau_{x y}}{\partial x}+\frac{\partial \sigma_{y y}^{\prime}}{\partial y}=\frac{\partial \Delta u}{\partial y},
\end{aligned}
$$

where $\sigma_{x x}^{\prime}$ and $\sigma_{y y}^{\prime}$ are the effective normal stresses in the horizontal and vertical directions, respectively, and $\tau_{x y}$ is the shear stress.

The soil elastic constitutive model can be written as:

$$
\begin{aligned}
\sigma_{x x}^{\prime} & =2 G\left[\frac{\partial u_{s}}{\partial x}+\frac{\mu_{s}}{1-2 \mu_{s}}\left(\frac{\partial u_{s}}{\partial x}+\frac{\partial w_{s}}{\partial y}\right)\right], \\
\sigma_{y y}^{\prime} & =2 G\left[\frac{\partial w_{s}}{\partial y}+\frac{\mu_{s}}{1-2 \mu_{s}}\left(\frac{\partial u_{s}}{\partial x}+\frac{\partial w_{s}}{\partial y}\right)\right], \\
\tau_{x y} & =G\left[\frac{\partial w_{s}}{\partial x}+\frac{\partial u_{s}}{\partial y}\right],
\end{aligned}
$$

where $G$ is the shear modulus of soil, and is related to Young's modulus $(E)$ as well as Poisson's ratio $\left(\mu_{\mathrm{s}}\right)$ 


$$
G=\frac{E}{2\left(1+\mu_{S}\right)} .
$$

Several boundary conditions are required to obtain the pore pressure $(\Delta \mathrm{u})$ and soil displacement $\left(u_{\mathrm{s}}\right.$ and $w_{\mathrm{s}}$ ). At the surface of the seabed, the vertical effective normal stress and shear stress are both set to zero, while the pore pressure is equivalent to the dynamic wave pressure $\left(p_{\mathrm{b}}\right)$ computed from the wave model

$$
\Delta \mathrm{u}=p_{b}, \sigma_{\mathrm{yy}}^{\prime}=0, \tau_{x y}=0 \text { at } y=h_{s} .
$$

The bottom of seabed is an impermeable rigid bottom, without displacements or vertical flow:

$$
\frac{\partial \Delta u}{\partial y}=u_{s}=w_{s}=0 \text { at } y=0 .
$$

Both lateral boundaries of the seabed are considered to be impermeable without horizontal displacement or flow motion [11]:

$$
\frac{\partial \Delta u}{\partial x}=u_{s}=0 \text { at } x_{b} \text { and } x_{e},
$$

where $x_{b}$ and $x_{e}$ are the horizontal coordinates at the beginning and the end in the sand tank, respectively.

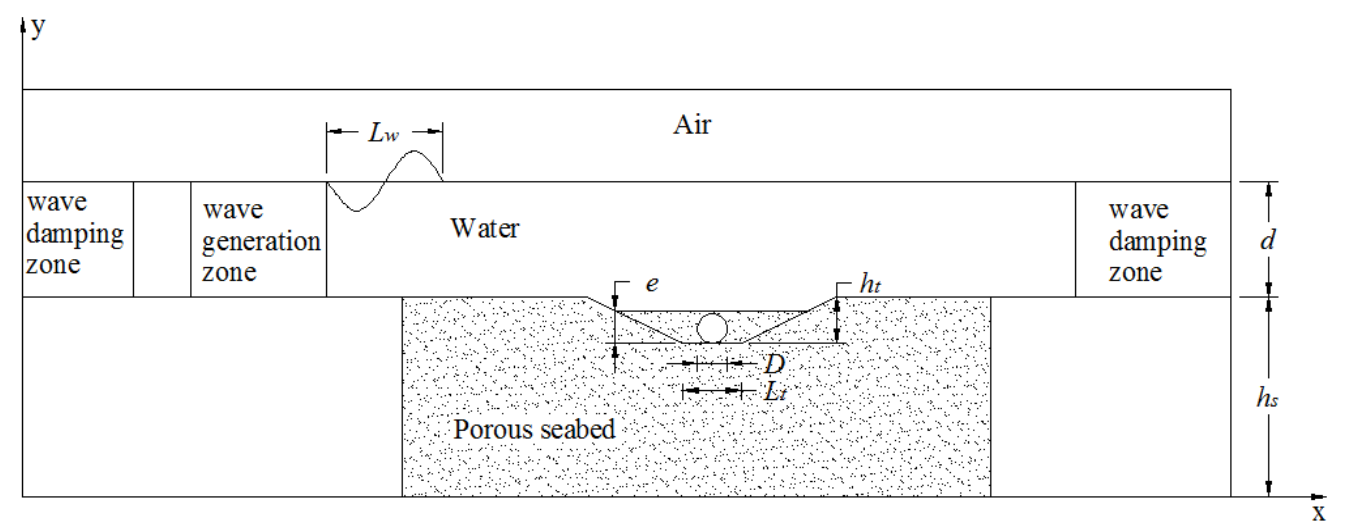

Figure 3. Wave-seabed-trenched pipeline interactions

\section{Results and discussion}

\subsection{Wave-seabed-trenched pipeline interactions}

As shown in Figure 4, the wave-induced pore-water pressure $(\Delta \mathrm{u})$ is periodically oscillatory, and the residual pore-water pressure is negligible in a sandy seabed. Such phenomena were observed in all tests conducted, and are ascribed to the fact that the grain size of the sediment used in this study is too large $\left(d_{50}=0.15 \mathrm{~mm}\right)$ to generate residual pore-water pressure. The pore-water pressure induced by the previous wave loading was fully dissipated before the next wave arrived. Figure 5 presents typical profiles of waves $(\eta)$ and pore-water pressures within the same wave period. Figure 5(a) compares the experimental water elevation with the results obtained from the analytical solution and the numerical model at the same point away from the right end of the wave generation zone. As can be seen in Figure 5(a), the simulated wave profile agrees overall with the laboratory measurements and the Stokes' 3rd-order wave theory, although the values of the wave trough amplitudes obtained from analytical solution are marginally smaller than those of the experimental results and numerical model. The wave crest amplitudes obtained from analytical solution are approximately identical to those of the experimental results and numerical model. It can be seen from Figure 5(a) that deviations around the wave trough and crest can be ignored, indicating that the laboratory results and numerical model are both accurate and reliable in simulating the water elevation. The simulated and measured dynamic pore pressures induced by wave action on the bottom of pipeline are plotted in Figure 5(b). In general, the simulated pore pressures agree well with the laboratory measurements. 

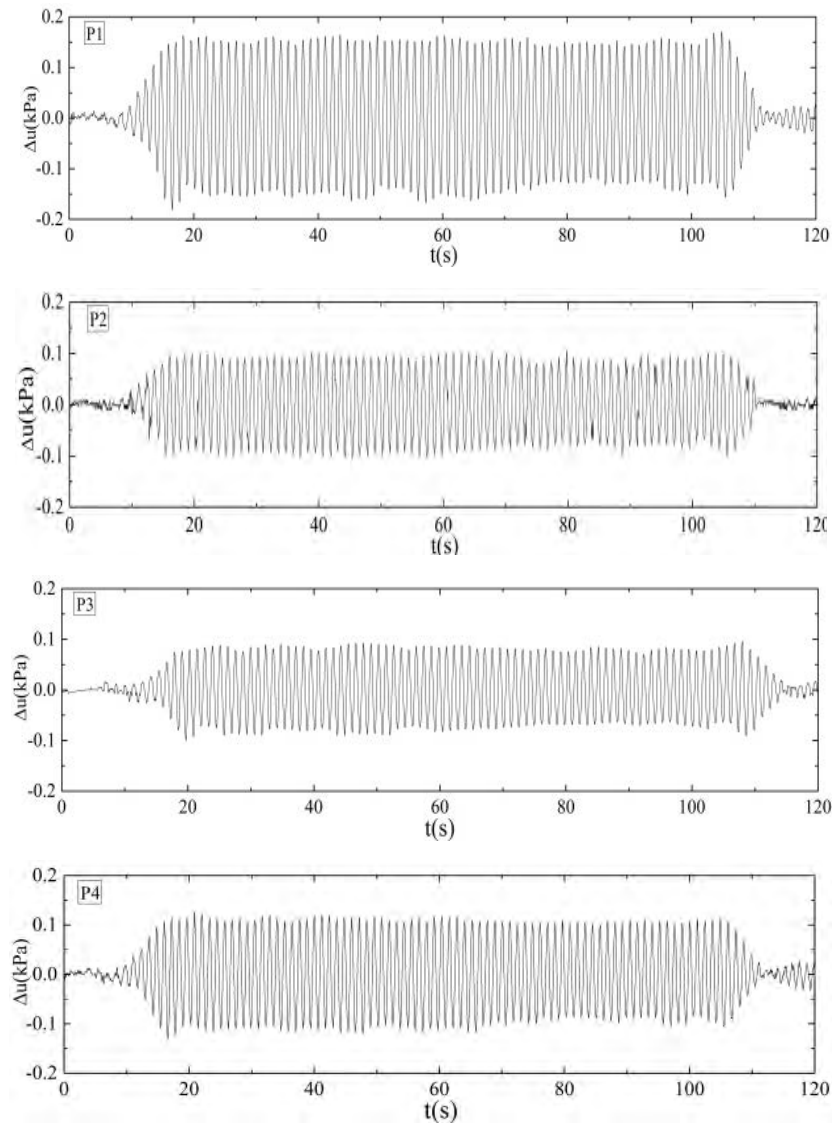

Figure 4. Pore-water pressure around fully buried pipeline with $d_{50}=0.15 \mathrm{~mm}, D=8 \mathrm{~cm}$

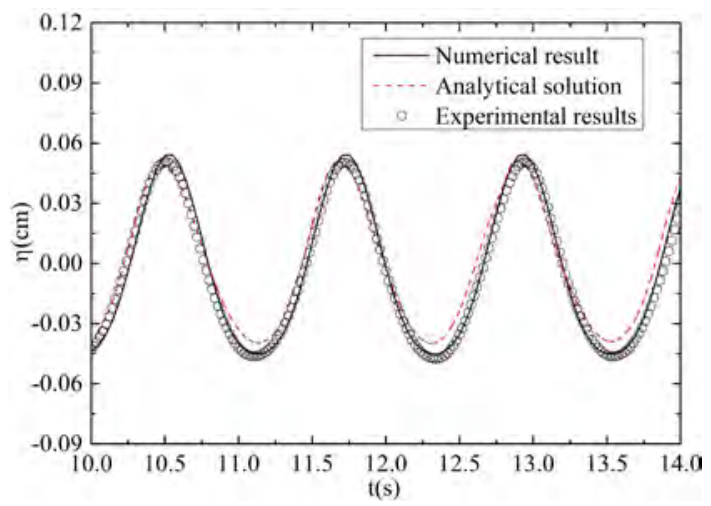

(a) water elevation

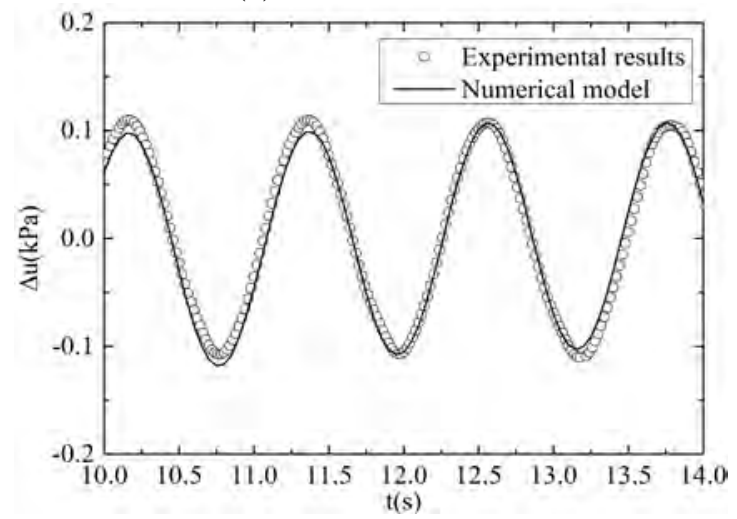

(b) excess pore-water pressure with $d_{50}=0.15 \mathrm{~mm}$

Figure 5. Typical profiles within several periods: (a) water elevation, and (b) excess pore-water pressure 
Pressure variations, including numerical model and experimental results, with full backfill and a pipeline diameter of $8 \mathrm{~cm}$, are shown in Figure 6. It can be seen that the amplitude of the pore pressures around the pipeline increase with increasing wave periods. Furthermore, the maximum amplitude of pore pressure $(|\Delta \mathrm{u}|)$ at the top of the pipeline is approximately twice as great as the minimum at the bottom, with a wave period $\mathrm{T}=1.6 \mathrm{~s}$. This is consistent with the conclusions of Pan and Wang [31]. Figure 7 presents the distributions of pore-water pressures in the seabed at the same wave phase (with wave trough passing the pipeline), with different wave conditions. It can be clearly seen from the figure that the wave parameters have a significant effect on the waveinduced dynamic pore pressures. The pore pressure above the pipeline is the smallest of all seabed positions with the wave trough passing over the pipeline. This result agrees well with Figure 6.
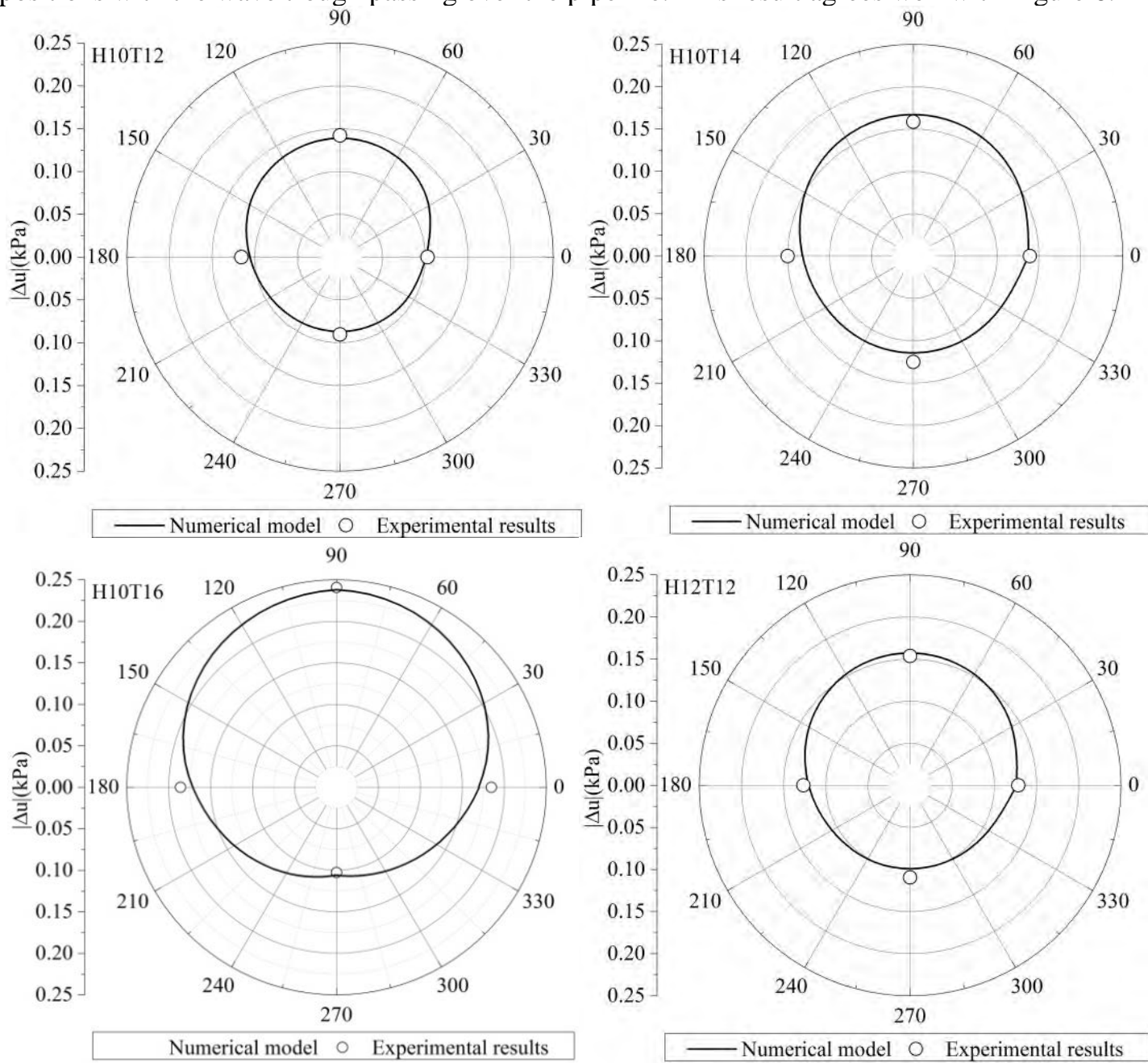

Figure 6. Distributions of amplitude of wave-induced excess pore-water pressure around pipeline with $d_{50}=0.15 \mathrm{~mm}$

Figures 8(a) and 8(b) present wave-induced pore pressures versus time at different depths for a sandy seabed with $\mathrm{H}=10 \mathrm{~cm}, \mathrm{~T}=1.2 \mathrm{~s}$, and $\mathrm{H}=10 \mathrm{~cm}, \mathrm{~T}=1.6 \mathrm{~s}$, respectively. The time series of pore-water pressures in Figure 8 are obtained from the laboratory experiments. As shown in Figure 8(b), the amplitude of pore-water pressure at P3 is only 55\% of that recorded at P1, indicating that the maximum amplitude is reduced by $45 \%$ between P1 and P3. Meanwhile, the results in Figure 8(b) show that there is no obvious phase lag of pore pressure between P1 and P3. Figure 8(a) shows a similar phenomenon of decreasing amplitude attenuation and no obvious phase lag in the deeper seabed. Chang et al. [32] indicated that a portion of the stresses will be shifted to soil particles through the frictional effect between soil particles and pore water, and propagate into deeper soil in the form of pressure waves as the depth increases. As the stresses transferred by the pipeline are faster than by soil particles and pore water, there is no obvious phase lag between P1 and P3. 


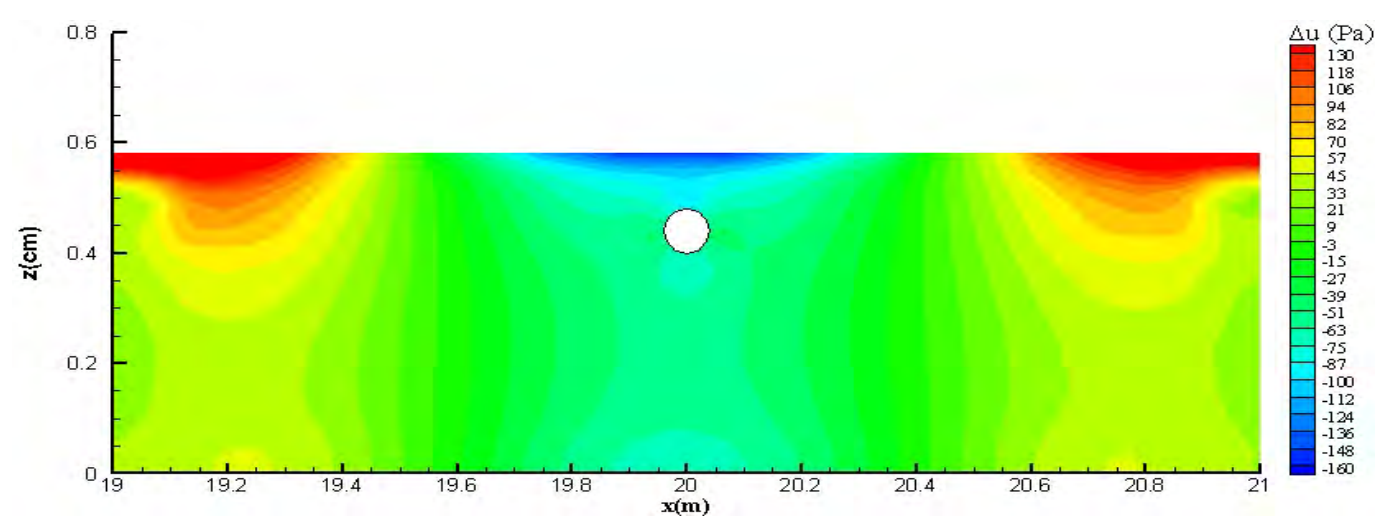

(a) $\mathrm{H}=10 \mathrm{~cm}, \mathrm{~T}=1.2 \mathrm{~s}$

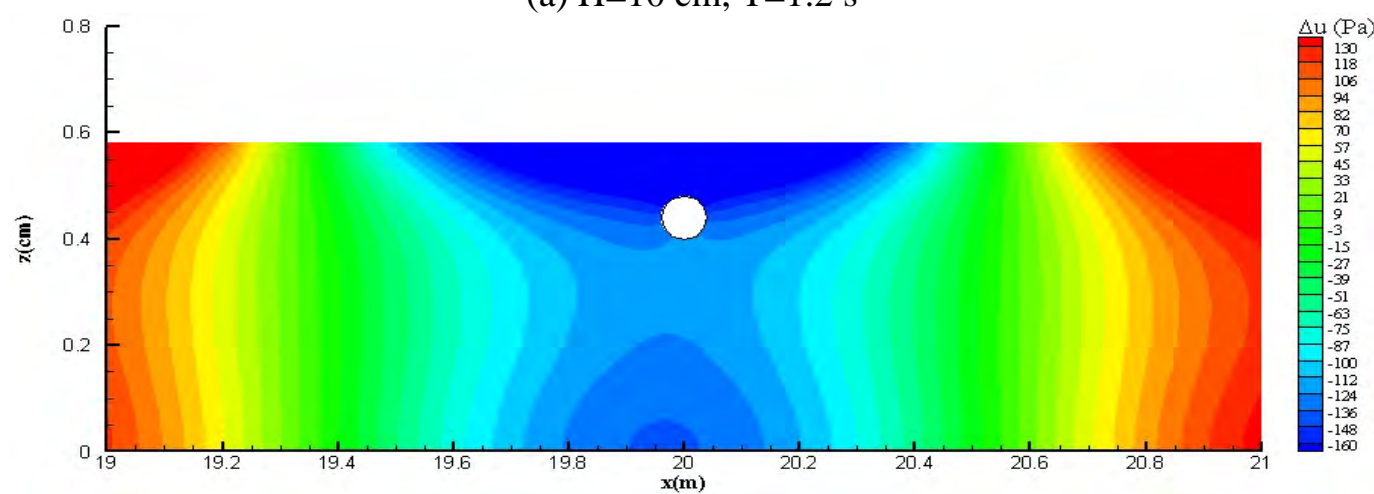

(b) $\mathrm{H}=10 \mathrm{~cm}, \mathrm{~T}=1.4 \mathrm{~s}$

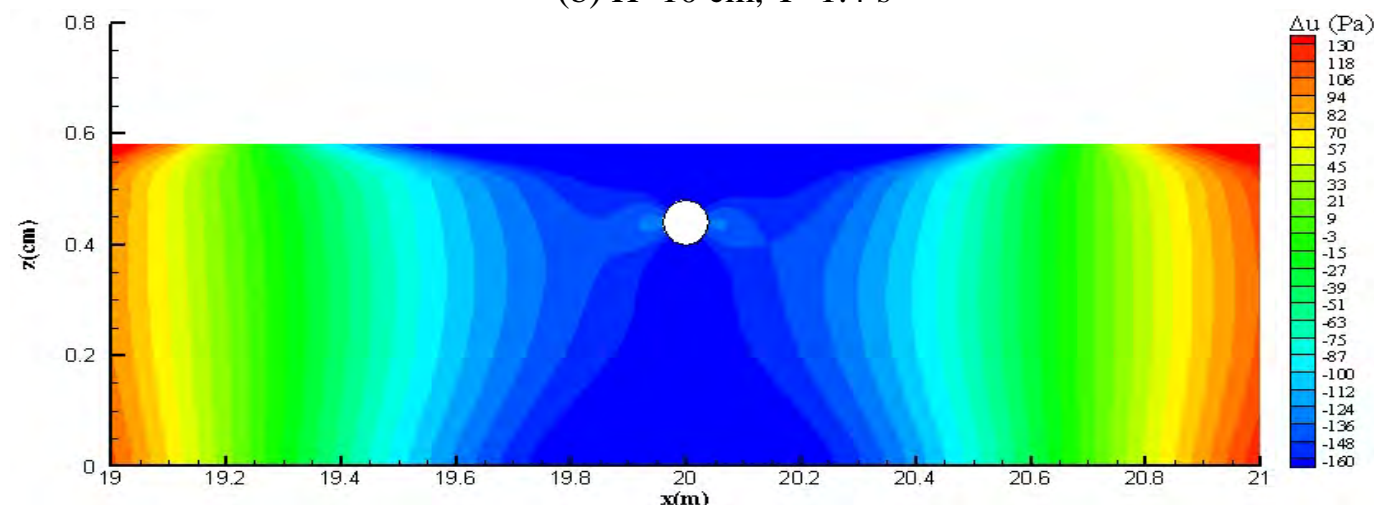

(c) $\mathrm{H}=10 \mathrm{~cm}, \mathrm{~T}=1.6 \mathrm{~s}$

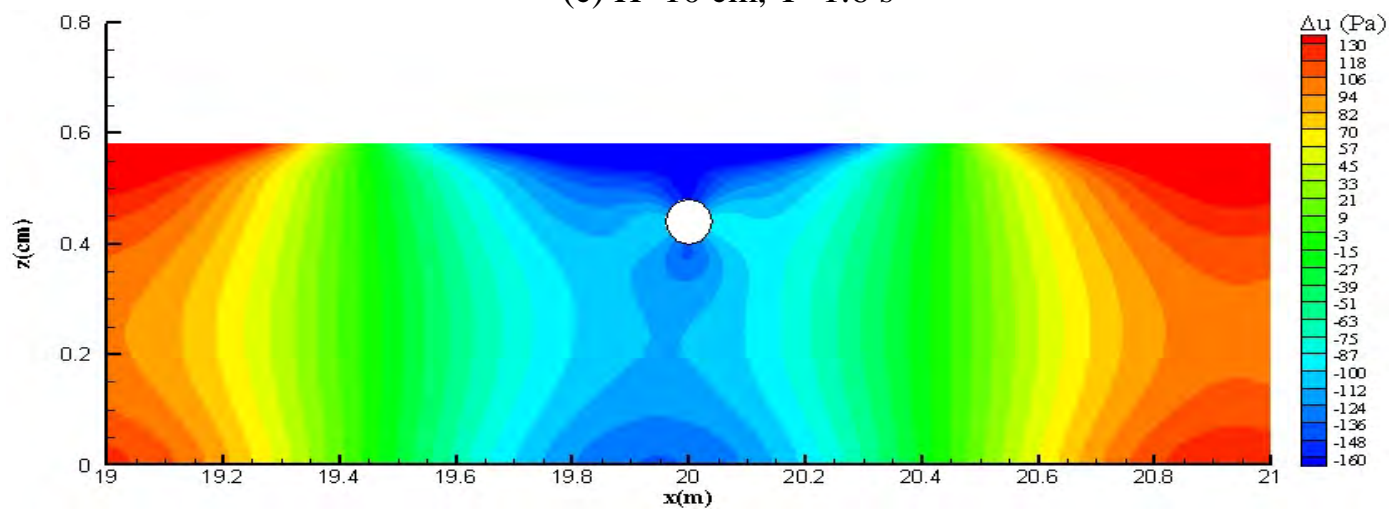

(d) $\mathrm{H}=12 \mathrm{~cm}, \mathrm{~T}=1.2 \mathrm{~s}$

Figure 7. Distribution of pore pressure in seabed with full backfill for same wave phase (with wave trough passing the pipeline): (a) $\mathrm{H}=10 \mathrm{~cm}, \mathrm{~T}=1.2 \mathrm{~s}$; (b) $\mathrm{H}=10 \mathrm{~cm}, \mathrm{~T}=1.4 \mathrm{~s}$; (c) $\mathrm{H}=10 \mathrm{~cm}$, $\mathrm{T}=1.6 \mathrm{~s}$; and (d) $\mathrm{H}=12 \mathrm{~cm}, \mathrm{~T}=1.2 \mathrm{~s}$ 

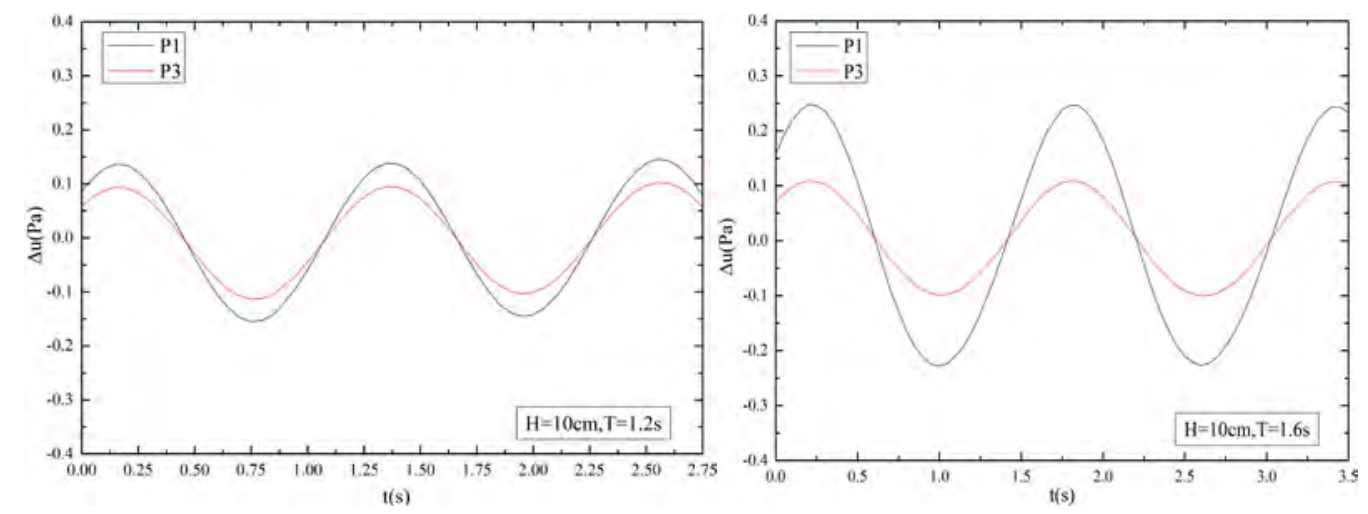

Figure 8. Excess pore-water pressure time series under sandy seabed conditions at depths $\mathrm{z}=10 \mathrm{~cm}$ (P1) and $\mathrm{z}=18 \mathrm{~cm}$ (P3): (a) $\mathrm{H}=10 \mathrm{~cm}, \mathrm{~T}=1.2 \mathrm{~s}$; and (b) $\mathrm{H}=10 \mathrm{~cm}, \mathrm{~T}=1.6 \mathrm{~s}$

\subsection{Effects of backfilled depth}

Protecting offshore pipelines is one of the critical issues in offshore pipeline engineering. In general, an effective approach for protecting the pipeline being damaged from fishing activities and oceanic loads (e.g., current and wave action) is to place a submarine pipeline inside a trench. The backfilled depth significantly affects the stability of pipeline. Typically, coarser sand can reduce the potential of wave induced instability. Therefore, coarse-grained sand is commonly selected as backfill material over the pipeline in the trench layer for pipeline protection. However, to reduce the project costs in offshore engineering, the backfill material is typically taken from material excavated from the seabed during trenching. Therefore, the characteristics of backfill sand are similar, or identical, to the sand around the trench when investigating the wave-induced dynamic seabed response around a pipeline in the trench both experimentally and with numerical models.

The amplitude of wave-induced excess pore pressure around the pipeline with manifold backfilled depths are shown in Figure 9. In this figure, the points $|\Delta \mathrm{u}|$ are measured radially from the centre of the circle. It is noted that the amplitude of pore water pressure around the pipeline first decreases, and then increases with increasing backfilled area thickness. The amplitudes of the oscillating pore pressure surrounding the pipeline increases from the bottom of pipeline to the top for different backfill depths, as wave-induced stresses transferring into the soil bed decrease with depth. This is consistent with previous studies [33-35]. Figure 10 shows the variation of normalised excess pore pressure amplitudes relative to backfilled depth. It can be seen that the variation of excess pore pressure amplitudes around the pipeline is significant with variation of relative backfilled depth. Palmer and King [35] indicated that a fully backfilled pipeline is more secure than a pipeline inside an open trench. However, Zhao et al. [13] and Zhao and Jeng [37, 38] reported that the possibility of pipeline instability with a backfilled depth of $1.375 \mathrm{D}$ is lower than for a fully backfilled pipeline. Recently, to protect the pipeline from the transient liquefaction threat, Lin et al. [14] reported that a moderate backfilled depth is considered to reach the seabed surface, or even up to one pipeline diameter above the seabed surface. As indicated in Figure 10, the measured amplitudes of excess pore pressure around a pipeline with backfilled depth $\mathrm{D}$, are smaller than those with other backfilled depths. It can be clearly seen that the measured excess pore-pressure amplitudes decrease abruptly as the backfilled depth increases from 0 to $\mathrm{D}$. The primary reason for this could be that the wave-induced excess pore-water pressure around the pipeline decreases with increasing backfilled depth at certain backfilled depths. This is consistent with previous studies [39]. The amplitude of the excess pore pressure in the vicinity of the pipeline increases significantly as the backfilled depth increases from $D$ to $9 D / 4$. This means that the backfilled depth has a significant effect on oscillating pore pressures in the vicinity of the pipeline. With a wave trough going through the trench, the distribution of pore pressures in the seabed with manifold backfilled depths (e/D= $=0,1 / 2,1,3 / 2$ and 2$)$ ) and full backfill $(e / D=9 / 4)$ are shown in Figure 11. It can be seen that the continuous change of pore pressure in the sand tank, with the relative backfilled depths, is similar to the measured variation of pore pressure around the pipeline with backfill depth. The pore pressure on the seabed is a minimum with a backfilled depth $\mathrm{D}$, and a maximum with full backfill or a backfilled depth of zero. The pore pressure at the 
bottom of the pipeline shows the same trend that pore pressure increases as the backfilled depth increases from 0 to $\mathrm{D}$, and then decreases when the backfilled depth increases from $\mathrm{D}$ to $9 \mathrm{D} / 4$. A trench with sufficient backfilled depth can eliminate the scour and liquefaction produced around the pipeline, and protect the pipeline from the threat of instability failure. According to previous studies $[1,40]$, the excess pore pressure gradient drives a seepage flow in vicinity of the pipeline, and excessive seepage flow is a major factor in the problem of pipeline instability. Figure 12 shows the difference of excess pore-water pressure at the top and bottom of the pipeline, under wave trough conditions, obtained from laboratory experiment. The figure presents the gradient of excess pore pressure.

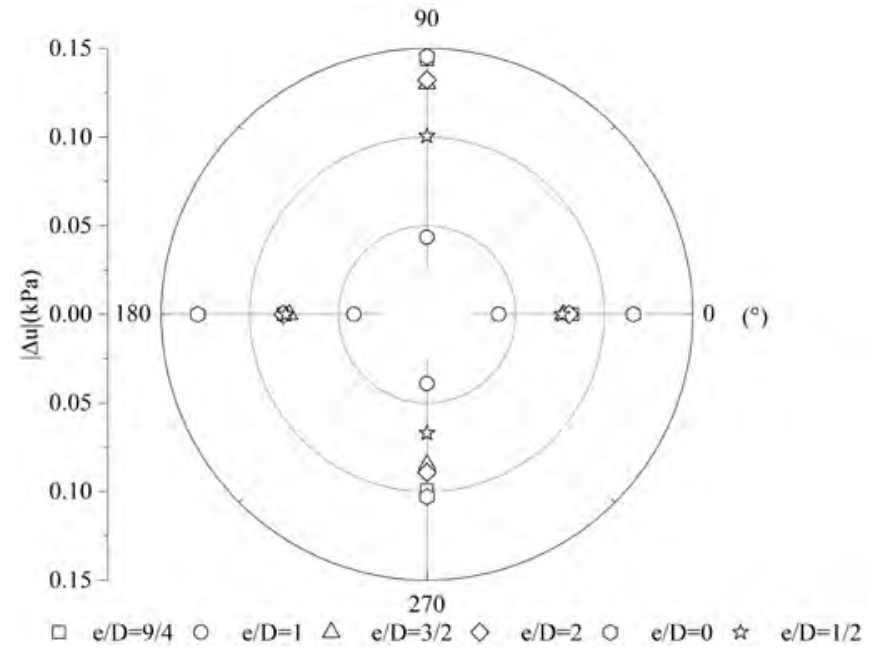

Figure 9. Influence of backfilled depths on amplitude of pore-water pressure around pipeline $(D=$ $8 \mathrm{~cm})$

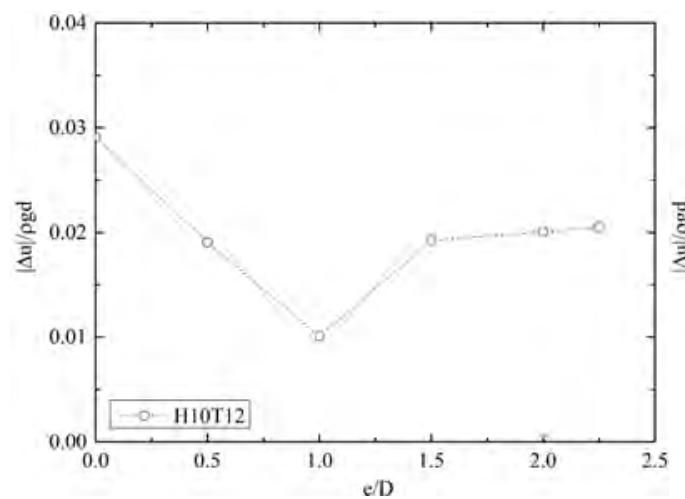

(a) $\mathrm{P} 4\left(\theta=0^{\circ}\right)$,

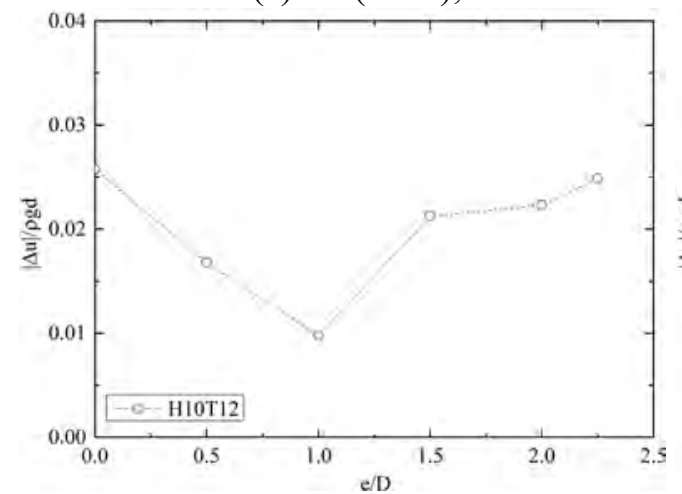

(c) $\mathrm{P} 2\left(\theta=180^{\circ}\right)$

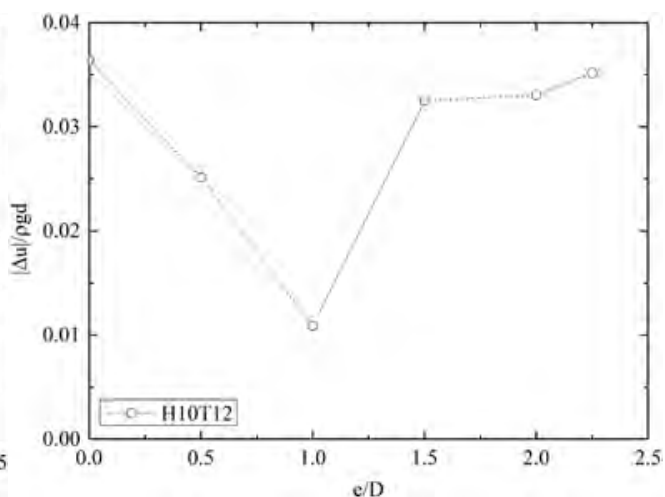

(b) $\mathrm{P} 1\left(\theta=90^{\circ}\right)$

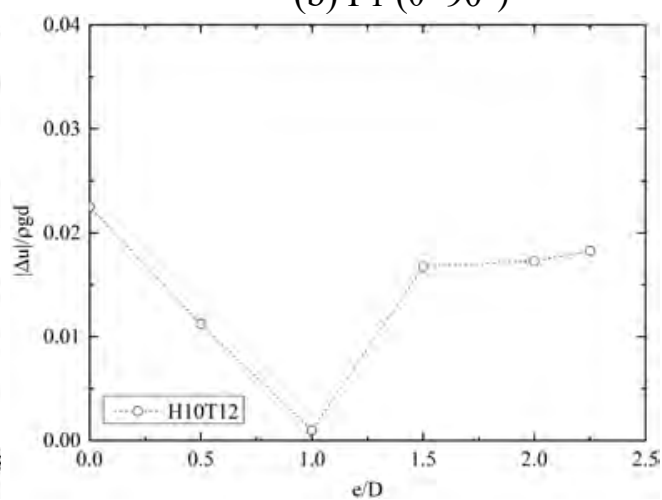

(d) P3 $\left(\theta=270^{\circ}\right)$

Figure 10. Variation of normalised pressure with relative backfilled depth: (a) P4 $\left(\theta=0^{\circ}\right)$, (b) P1 $\left(\theta=90^{\circ}\right),(\mathrm{c}) \mathrm{P} 2\left(\theta=180^{\circ}\right)$, and (d) P3 $\left(\theta=270^{\circ}\right)(D=8 \mathrm{~cm})$ 


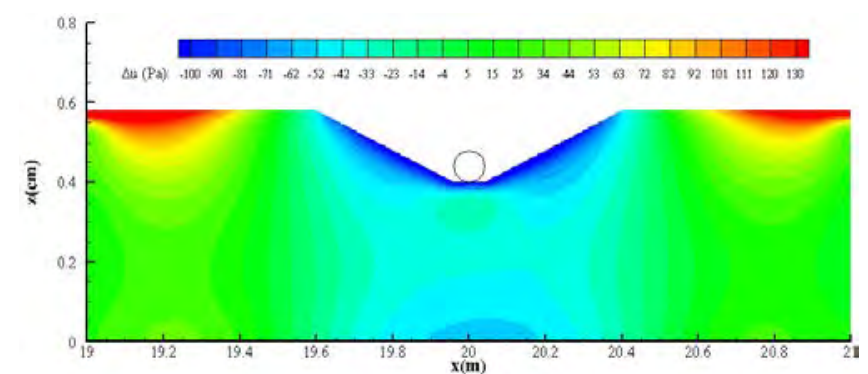

(a) $e / D=0$

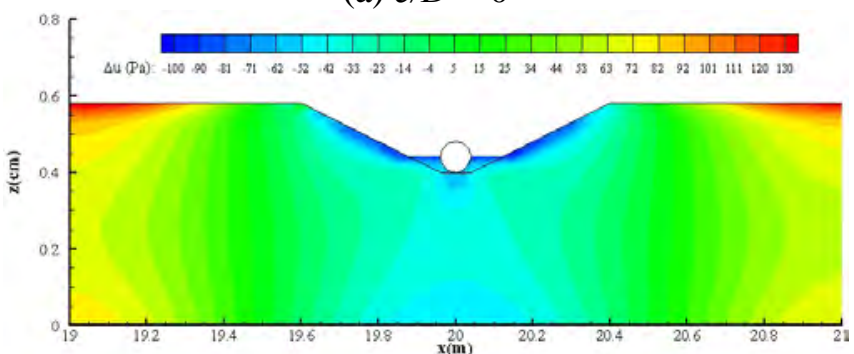

(b) $e / D=1 / 2$

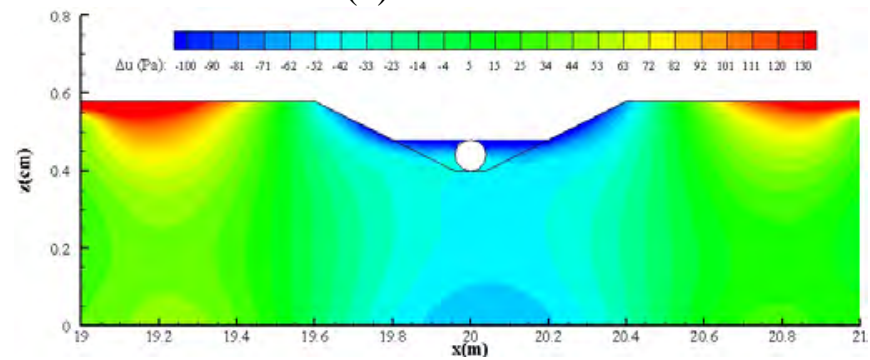

(c) $e / D=1$

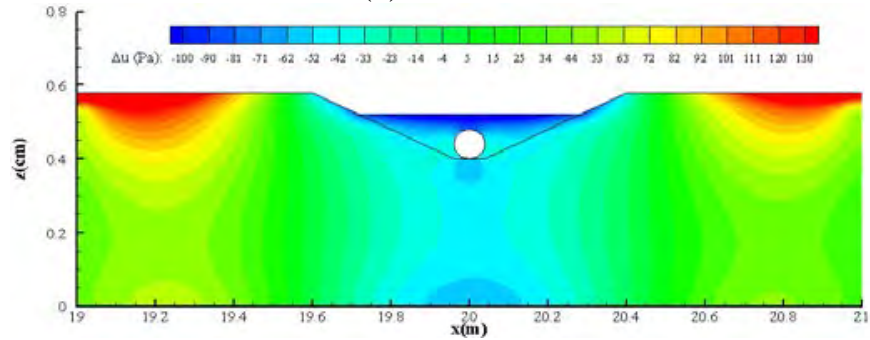

(d) $e / D=3 / 2$

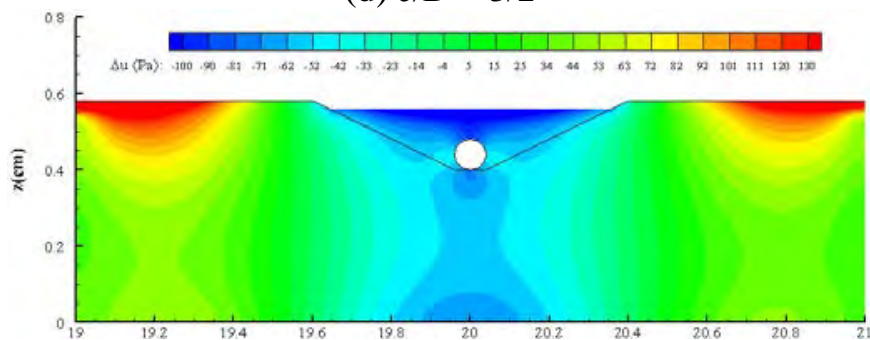

(e) $e / D=2$

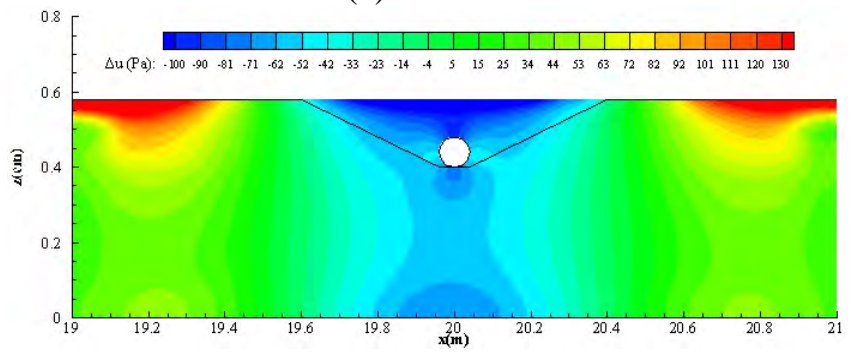

(f) full backfill $(e / D=9 / 4)$

Figure 11. Distribution of pore pressure in seabed at same wave phase (with wave trough passing the pipeline) 


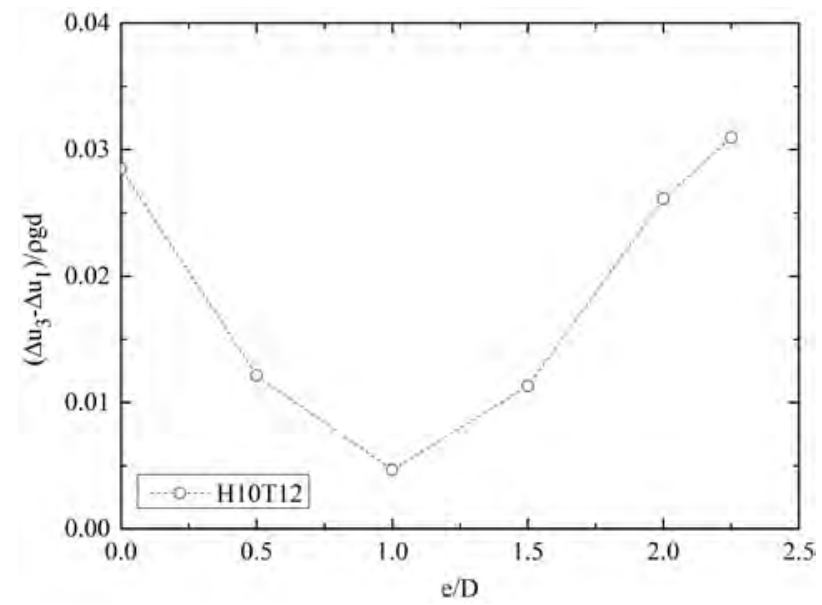

Figure 12. Difference of excess pore-water pressure at top and bottom of pipeline under wave trough conditions with different backfilled depths $(D=8 \mathrm{~cm})$

\subsection{Influences of backfill soil type}

In the previous example, the effect of the backfilled depth $(e / D)$ on the pore pressure was investigated. In this example, three sizes of backfill sands $\left(d_{50}=0.15 \mathrm{~mm}, d_{50}=0.30 \mathrm{~mm}\right.$, and $d_{50}$ $=0.50 \mathrm{~mm}$ ) are chosen for the following parametric study. The fully backfilled case is considered here. It can be seen from Figure 13 that the pore pressure amplitude around the pipeline is strongly influenced by the parameters of the covering layer. The pore pressure amplitude around the pipeline within a full trench layer increases with increasing median diameter. According to the experimental results of sandy sediment (Table 1), the permeability of soil increases with increasing median diameter. Therefore, the variation of pore pressure amplitude is strongly associated with the permeability of the backfill sand. The pore pressure amplitude around the pipeline decreases with increasing depth, and the vertical decay rate of the pore pressure decreases with increasing backfill sand median size. The decay rate is the ratio of the difference of porewater pressure at the top and bottom of the pipeline, to the pore pressure at the top of the pipe. The growth rate of pore pressure amplitude at the bottom of pipeline is approximately twice as great as that at the top. The growth rate is the ratio of the difference of pore pressure between $d_{50}=0.15$ $\mathrm{mm}$ and $d_{50}=0.50 \mathrm{~mm}$, to the pore pressure with $d_{50}=0.15 \mathrm{~mm}$, at a given point. This can be explained by the fluid-dominated mechanism for attenuation of pore-water pressure reported by Tisato and Quintal [41], that shows that the propagation of pore pressure in the seabed is only via pore water.

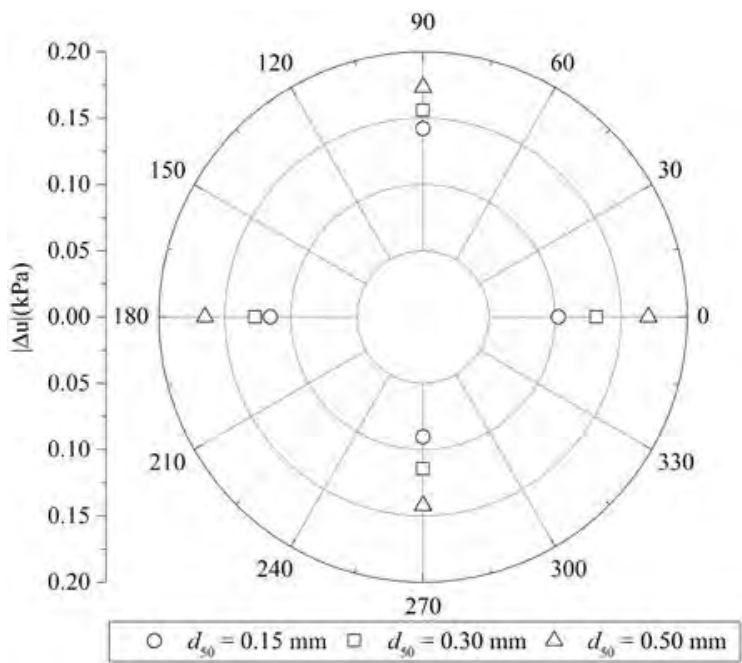

Figure 13. Amplitude of wave-induced pore-water pressure around pipeline with trench soil with various median diameters 
The effect of backfill material median diameter of the backfill material $\left(d_{50}\right)$ on the pore pressure around the pipeline is illustrated by both the numerical model and experimental results in Figure 14. It can be seen that the amplitude of the oscillatory pore pressure in the numerical model is lower than that observed in the experimental results. The amplitude of pore pressure around the pipeline is significantly affected by the permeability of the backfill materials. The coarser the backfill sand, the higher the pore pressure is around a buried pipeline. This could be because the permeability of the seabed increases with larger backfill materials, and the permeation loss of pore pressure in the seabed decreases. For example, the decay rate of pore pressure amplitude from the top of pipeline to the bottom is approximately $18 \%$ with $d_{50}=0.5 \mathrm{~mm}$, and approximately $36 \%$ with $d_{50}=0.15 \mathrm{~mm}$.

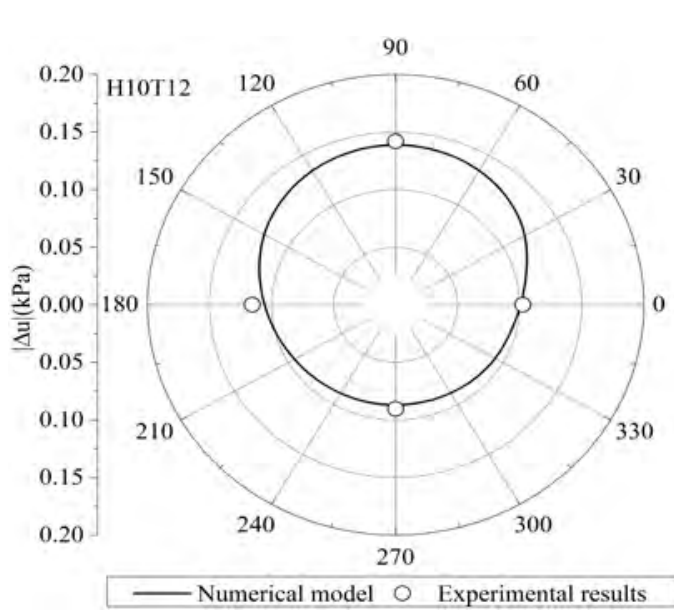

(a) $d_{50}=0.15 \mathrm{~mm}$

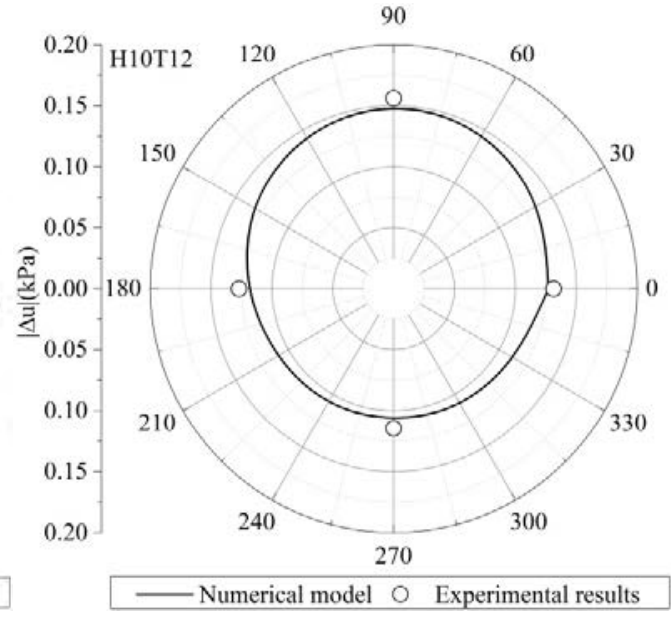

(b) $d_{50}=0.30 \mathrm{~mm}$

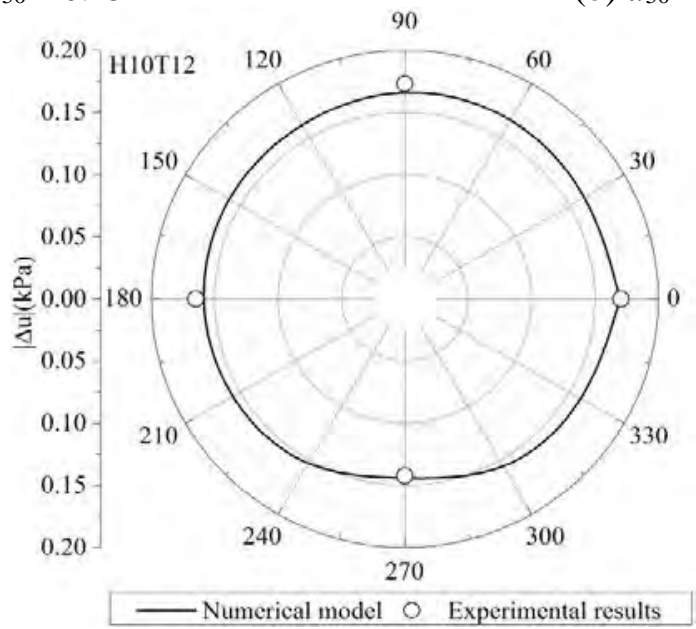

(c) $d_{50}=0.50 \mathrm{~mm}$

Figure 14. Distributions of amplitude of wave-induced pore-water pressure around pipeline: (a) $d_{50}=0.15 \mathrm{~mm}$, (b) $d_{50}=0.30 \mathrm{~mm}$, and (c) $d_{50}=0.50 \mathrm{~mm}$

Figure 15 presents the distributions of wave-induced pore pressure in the vicinity of the pipeline. It can be seen that the maximum pore pressure occurs on the trench surface, and the minimum under the trench when the wave crest crosses the trench. The pore pressure in the trench increases with an increasing median diameter. In general, the change of backfill sand median size leads to a discernible variation in the distribution of pore pressures. A detailed comparison of pore pressure for different backfill sand is shown in Figure 15, indicating significant differences in terms of wave-induced pore pressures. The coarser the backfill sand, the smaller the influence of the pipeline on the pore pressure in the seabed. As can be seen in Figure 15(a), the pore pressures in the circular region under the pipeline, and the semi-circular area at the bottom of the sediment basin, are greater than at other points under the trench. Compared to the change in the pore pressure under the trench in Figure 15(a), the variations of pore pressure in the same area in Figure 15(b) exhibit no obvious differences that can be obtained from the diminishing area with greater 
pore pressures under the trench. Figure 15(c) indicates that the variation of pore pressure under the trench is gradual, with no significant increase, and the effects of the pipeline on pore pressure in the seabed is the smallest of the three cases. The permeability of backfilled soil increases as the median size increases. The coarser the backfill sand, the higher the oscillated pore pressure is at the bottom of a buried pipeline.

Figure 16 shows the difference between excess pore pressure at the top and bottom of the pipe, with a wave trough passing over the pipe. In the case of $\mathrm{H}=10 \mathrm{~cm}, \mathrm{~T}=1.2 \mathrm{~s}$, it is found that the difference of pore pressure decreases with an increasing median diameter of backfilled material. According to the previous studies $[1,40]$, when the difference of excess pore pressure at the top and bottom of the pipeline is sufficiently great, an instability failure of the pipeline will occur. The reason why the pore pressure gradient decreases with an increasing backfill material median diameter could be that the permeability of the backfill increases as the median diameter of the backfill material increases. As a result, the possibility of pipeline instability decreases when the median diameter of the backfill material increases from $0.15 \mathrm{~mm}$, through $0.3 \mathrm{~mm}$, to $0.5 \mathrm{~mm}$.

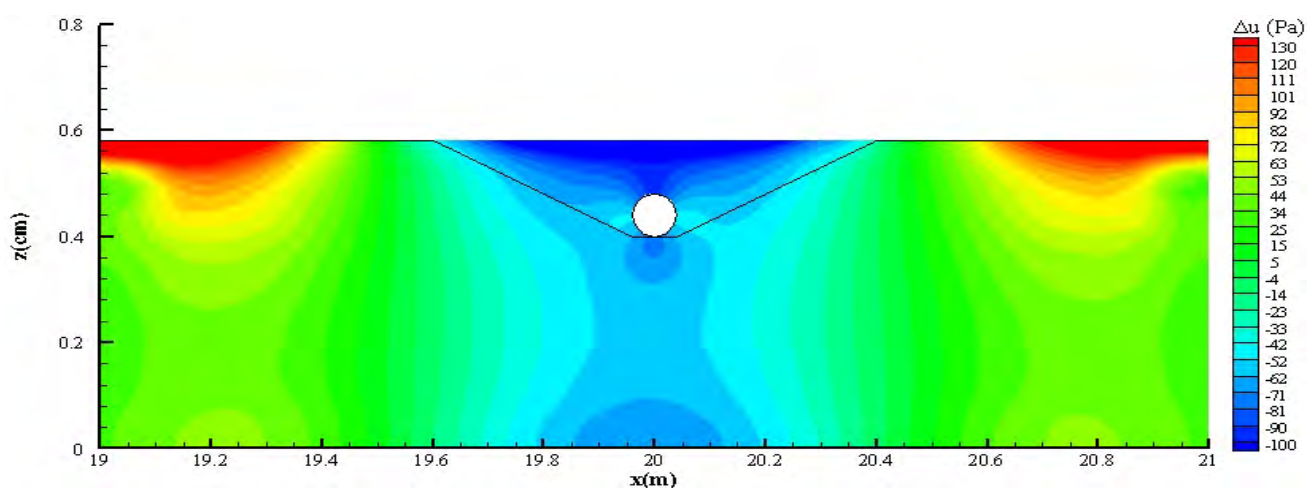

(a) $d_{50}=0.15 \mathrm{~mm}$

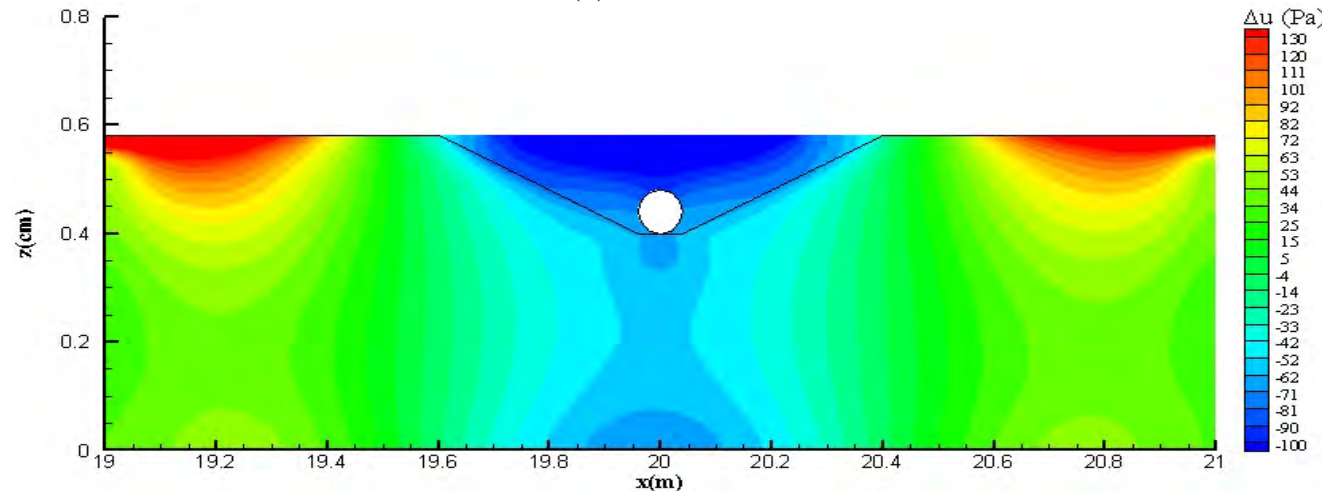

(b) $d_{50}=0.30 \mathrm{~mm}$

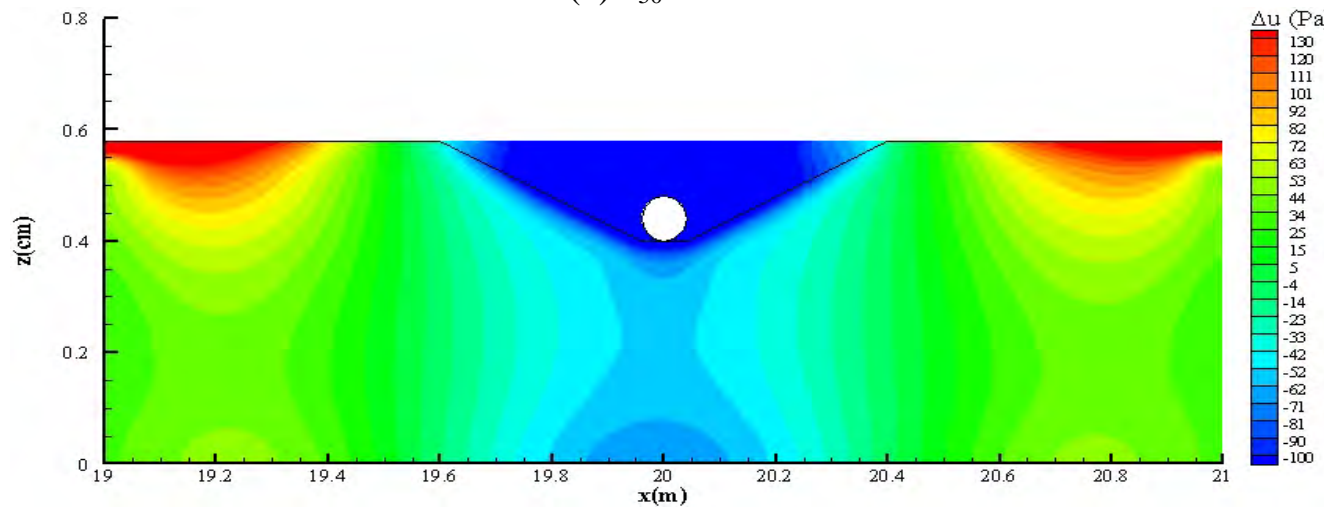

(c) $d_{50}=0.50 \mathrm{~mm}$

Figure 15. Distribution of pore pressure in seabed at same wave phase (under wave trough passing pipeline): (a) $d_{50}=0.15 \mathrm{~mm}$, (b) $d_{50}=0.30 \mathrm{~mm}$, and (c) $d_{50}=0.50 \mathrm{~mm}(e=18 \mathrm{~cm}, D$ $=8 \mathrm{~cm}$ ) 


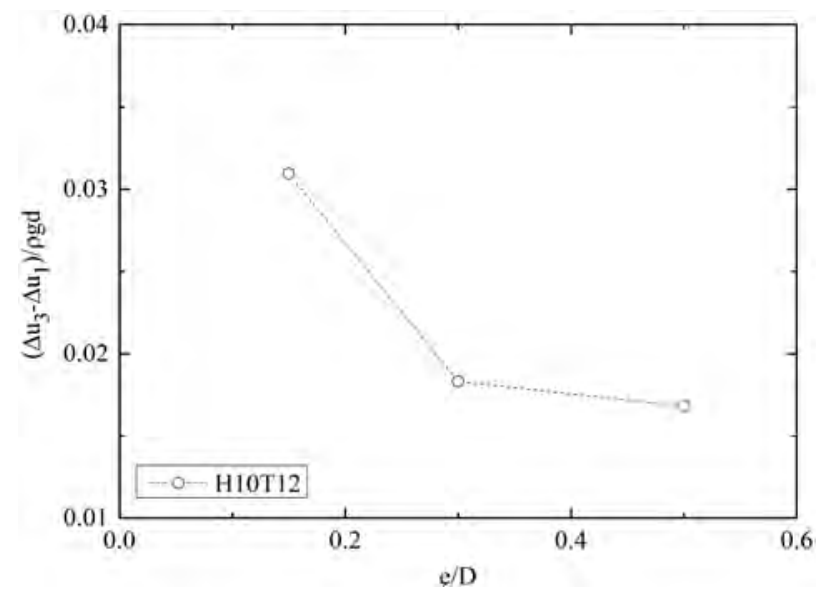

Figure 16. Difference of excess pore-water pressure between top and bottom of pipeline under wave trough with different median diameters $(e=18 \mathrm{~cm}, D=8 \mathrm{~cm})$

\subsection{Effects of pipeline diameter}

Not only do the backfilled depth and backfilled sand type influence the oscillating pore pressure around a pipeline, but the pipe diameter also has a visible effect on the dynamic response around the pipeline. Figure 17 shows the variation of the pore pressure amplitudes around the pipeline for the three different pipe diameters used in the experiment. It can be seen that the pore-pressure amplitudes around the pipeline increase initially, and then decrease with increasing pipe diameter. The pore-pressure amplitudes, with $D=6 \mathrm{~cm}$, around the pipeline fall between those with $D=8$ $\mathrm{cm}$ and $D=10 \mathrm{~cm}$. In general, a portion of the stresses will be shifted to the soil particles through the frictional effect between the soil particles and pore water, and propagate into deeper soil in the form of pressure waves as the depth increases. A pipeline in the seabed will break the propagation pattern of pore pressure in the vicinity of the pipeline. Because the submerged weight of the pipeline varies with different diameters, the effect on the propagation of pore pressure into deeper soil also differs. The pore-pressure amplitudes decay significantly from the top of pipeline to the bottom, while the amplitude attenuation rate between the top and bottom of the pipeline increases with increasing pipeline diameter. For example, the decay rates of pore-pressure amplitude are $6.20 \%, 4.54 \%$, and $3.58 \%$ for pipeline diameters $6 \mathrm{~cm}, 8 \mathrm{~cm}$, and $10 \mathrm{~cm}$, respectively. As shown in Figure 18, the pore-pressure amplitudes obtained from the numerical model agree well with the measured results. In addition, it can be also seen that the measured results are marginally greater than the numerical results. The pore-pressure amplitude at the bottom of the pipeline (P3) is marginally smaller than that on the two sides of the pipeline (P2 and P4). This phenomenon can be explained by the fact that the submerged weight of the pipeline is added to the seabed under the pipeline. As a result, the pore pressure amplitude does not decrease significantly as the depth increases.

Figure 19 shows the distribution of pore pressure in the seabed at the same wave phase (under the wave crest). It can be seen that the effect of pipeline diameter on the pore pressure at the bottom of the sediment basin is negligible, but the effect is significant at the bottom and on the two sides of the pipeline. The influence of pipeline diameter on the dynamic response of the seabed is obvious in the horizontal direction, but is insignificant in the vertical direction, and the phenomenon happens only around the pipeline. The change of diameter leads to a variation of seepage paths and submerged unit weight, and this alters the propagation of pore pressure in the seabed. This could be the primary reason why the effect of pipeline diameter on the pore pressure simply manifests near the pipeline. The variation of the maximum difference of excess pore pressure at the top and bottom of the pipeline under the wave trough passing over the pipeline is shown in Figure 20. It can be seen from the figure that the pore pressure gradient first increases, and then visibly decreases as the pipeline diameter increases. It can be concluded that the effect of the pipeline diameter on possible instability of the pipeline is evident. According to previous investigations [1,36], the possibility of instability of the pipe with $D=8 \mathrm{~cm}$ is greater than for the other two diameters $(D=6 \mathrm{~cm}$ and $10 \mathrm{~cm})$. 


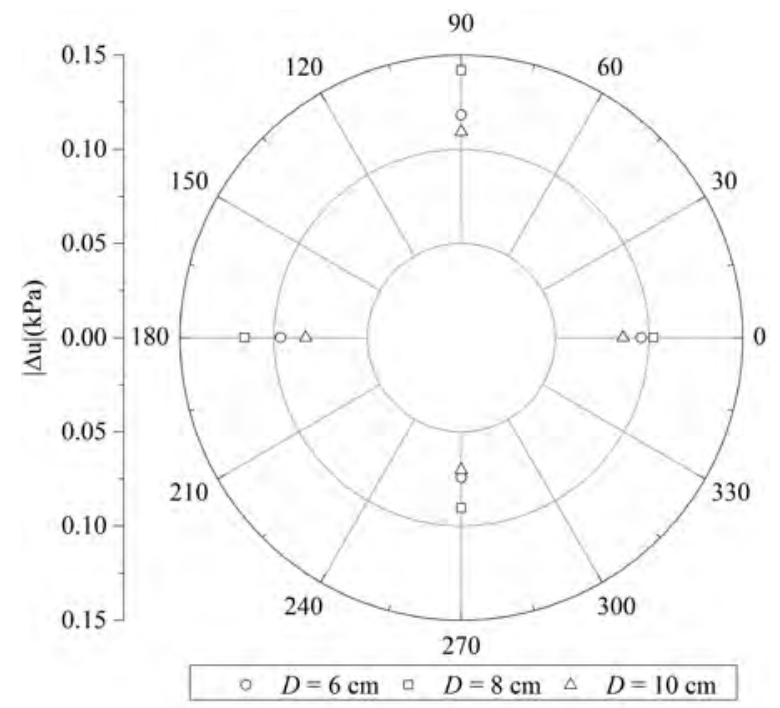

Figure 17. Influence of pipeline diameter on wave-induced pore-water pressure around fully backfilled pipeline

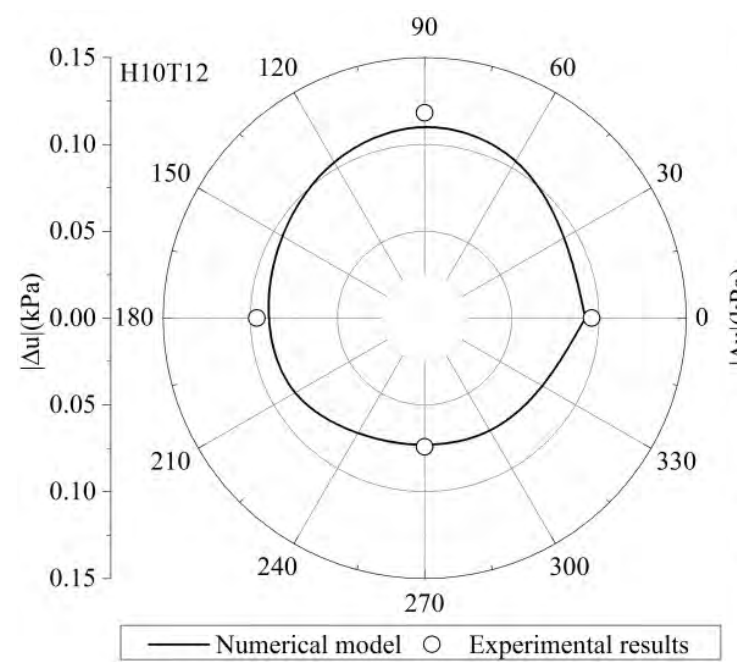

(a) $D=6 \mathrm{~cm}$

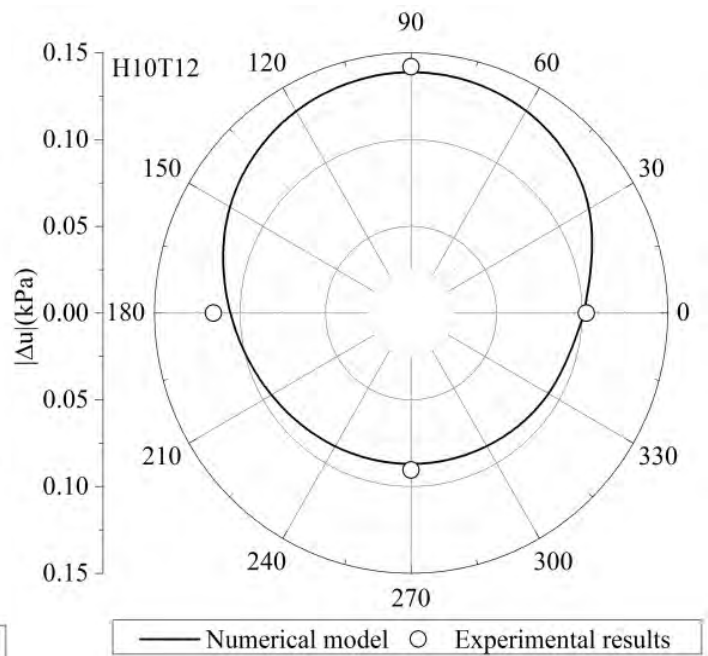

(b) $D=8 \mathrm{~cm}$

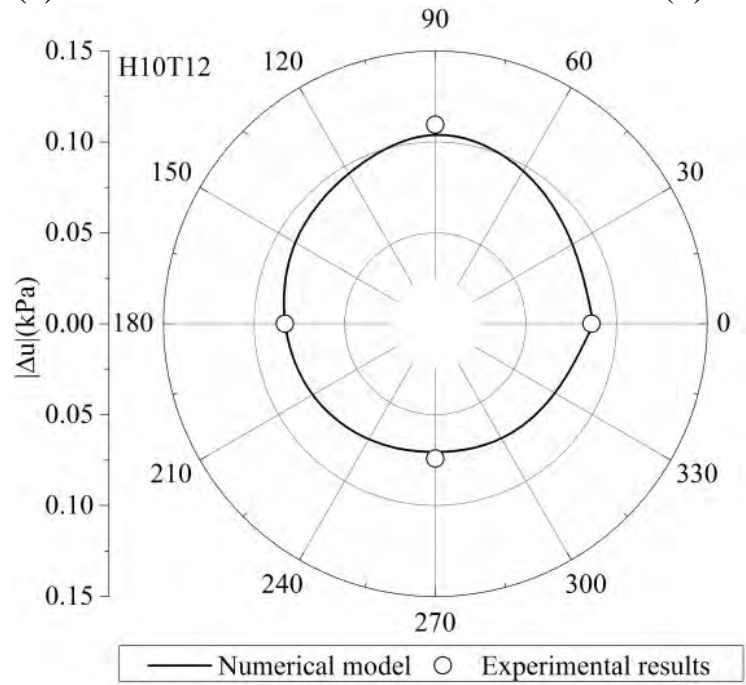

(c) $D=10 \mathrm{~cm}$

Figure 18. Amplitude of wave-induced pore-water pressure around fully backfilled pipeline with various pipeline diameters: (a) $D=6 \mathrm{~cm}$, (b) $D=8 \mathrm{~cm}$, and (c) $D=10 \mathrm{~cm}$ 


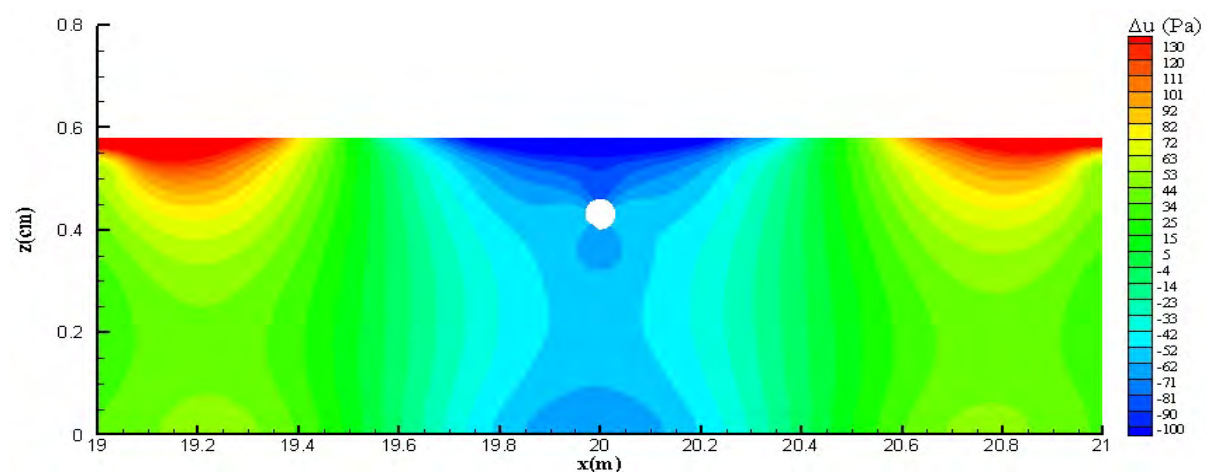

(a) $D=6 \mathrm{~cm}$

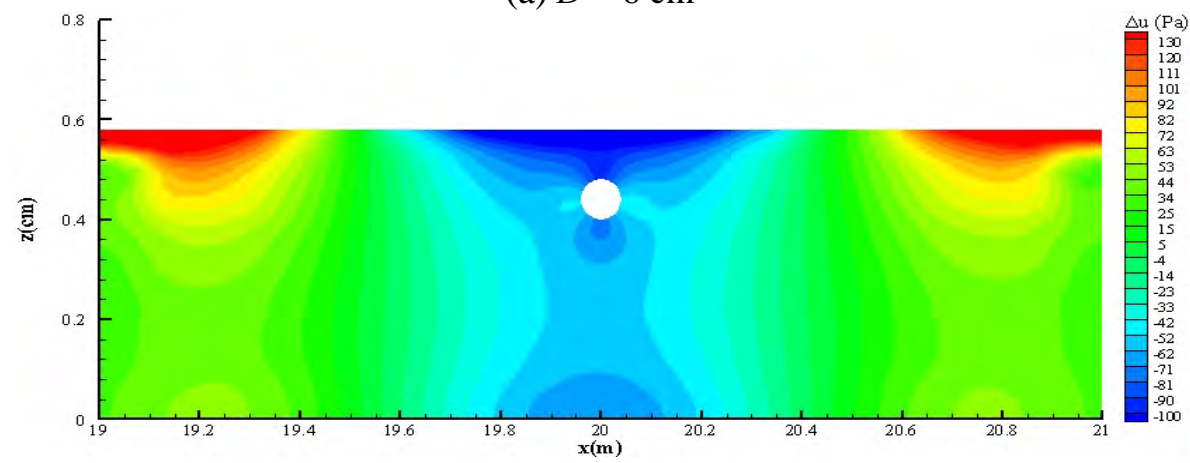

(b) $D=8 \mathrm{~cm}$

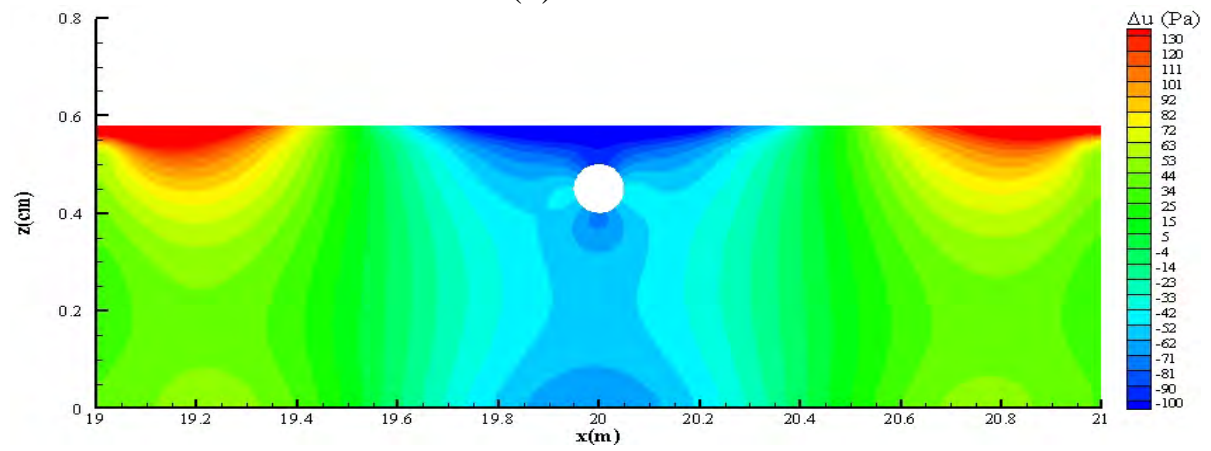

(c) $D=10 \mathrm{~cm}$.

Figure 19. Distribution of pore pressure in seabed with $d_{50}=0.15 \mathrm{~mm}$ at same wave phase (under wave trough passing the pipeline): (a) $D=6 \mathrm{~cm}$, (b) $D=8 \mathrm{~cm}$, and (c) $D=10 \mathrm{~cm}$.

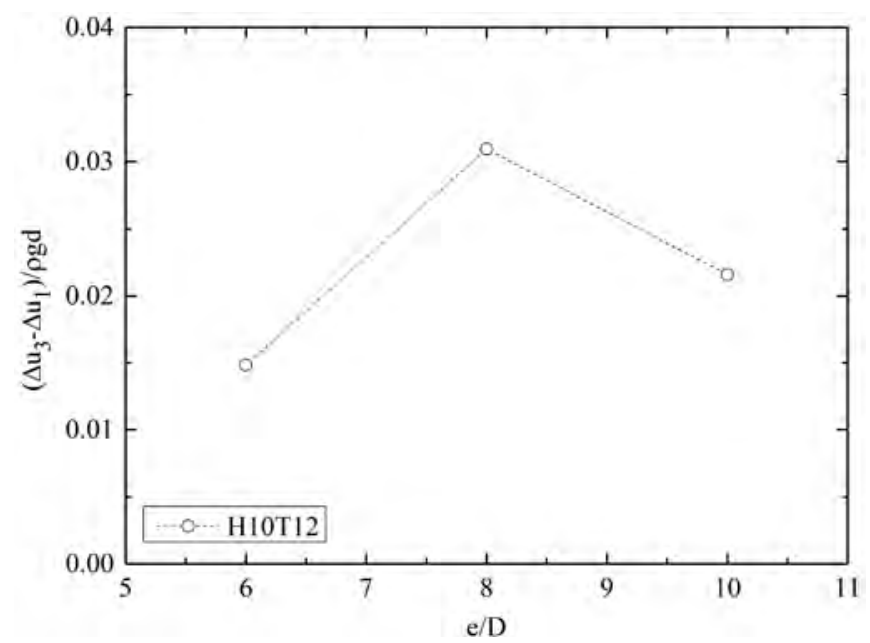

Figure 20. Difference of excess pore-water pressure at top and bottom of pipeline under wave trough with different pipeline diameters $(e=18 \mathrm{~cm}, D=8 \mathrm{~cm})$ 


\section{Conclusion}

In this study, a comprehensive investigation was carried out on different soil dynamic responses around a pipeline, to regular waves in a sandy seabed, by a series of experimental flume tests and an integrated WSSI model. In the laboratory experiments, four wave conditions and three types of sand were used. Six different pipeline backfilled depths and three pipeline diameters were considered. In the numerical model, the ocean wave was described by the RANS equations, and the dynamic response of the seabed under the wave actions was governed by Biot's equations. The major conclusions drawn from the study are as follows.

(1) The amplitude of the wave-induced pore-water pressure around pipeline decreased towards the bottom of the pipeline, and increased with increasing wave period. The pore pressures between the top and the bottom of pipeline had no phase lag. The measured pore pressures exhibited good agreement with the numerical results.

(2) The pore-pressure amplitude around the pipeline first increased, and then decreased, and finally increased with increasing backfilled area thickness. The pore pressure in the seabed was a minimum with backfilled depth $D$, and a maximum with full backfill or a backfilled depth of zero. As a result, the possibility of pipeline instability with a backfilled depth $D$ was smaller than that of a fully backfilled pipeline. The amplitudes of oscillating pore pressure around the pipeline increased from the bottom to the top of the pipeline at different backfill depths, as wave-induced stresses transferred into the soil bed decreased with depth.

(3) The pore pressures measured through the soil depth indicated that pore pressures in these three types of soils responded differently to wave loading with the presence of the pipeline. The measured pore pressure amplitudes increased with increasing backfilled material median diameter, and increasing depth. The growth rate of pore pressure at the bottom of pipeline was approximately twice as great than at the top. The decay rate of pore-pressures amplitudes decreased with increasing backfilled sand median size.

(4) The pore-pressure amplitudes around the pipeline increased initially, and then decreased with increasing pipe diameter. The effect of pipeline diameter on the pore pressure at a distance from the pipeline was negligible, but around the pipeline was significant. The influence was obvious along the depth, but was insignificant in the vertical direction around the pipeline.

\section{Acknowledgments}

The authors are grateful for the support from the national key research and development program of China (2017YFC1404200), the research grants of Jiangsu (BK20150804), the marine renewable energy research project of State Oceanic Administration (GHME2015GC01), and Open Foundation of State Key Laboratory of Hydrology-Water Resources and Hydraulic Engineering, Hohai University (Grant No: 2016491011).

\section{References}

[1] B.M. Sumer. Liquefaction Around Marine Structures. World Scientific, New Jersey (2014).

[2] B.M. Sumer, J. Fredsøe. The Mechanics of Scour in the Marine Environment. World Scientific Publishing Co Pte Ltd (2002).

[3] J.B. Herbich, R.E. Schiller, W.A. Dunlap, R.K. Watanabe. Seafloor scour-design guidelines for ocean-founded structures. Marcel Dekker Inc. New York (1984).

[4] J.T. Christian, P.K. Taylor, J.K.C. Yen, D.R. Erali. Large diameter underwater pipeline for nuclear power plant designed against soil liquefaction. Offshore Technology Conference 597 (1974), pp. 597-602. 
[5] S. Neelamani, K. Al-Banaa. Wave force variation due to burial of submarine pipelines in uniformly graded and low hydraulic conductivity soil. Applied Ocean Research 35 (2012), pp. $47-55$.

[6] J.S. Zhang, J.H. Zheng, C. Zhang, D.S. Jeng, Y.K. Guo. Numerical study on the interaction between waves and twin pipelines in sandy seabed. Journal of Coastal Research. Special Issue No 65 (2013), pp. 428-433.

[7] H. MacPherson. Wave forces on pipelines buried in permeable seabed. Journal of Waterway, Port, Coastal and Ocean Division, ASCE 104(4) (1978), pp. 407-419.

[8] A.H. Cheng, P.L. Liu. Seepage force on a pipeline buried in a poroelastic seabed under wave loadings. Applied Ocean Research 8 (1986), pp. 22-32.

[9] F.P. Gao, Y.X. Wu. Non-Linear Wave Induced Transient Response of Soil Around A Trenched Pipeline. Ocean Engineering 33 (2006), pp. 311-330.

[10] D.S. Jeng, L. Cheng. Wave-induced seabed instability around a buried pipeline in a poroelastic seabed. Ocean Engineering 27 (2000), pp. 127-146.

[11] X. Zhou, D.S. Jeng, Y. Yan, J. Wang. Wave-induced multi-layered seabed response around a buried pipeline. Ocean Engineering 72 (2013), pp. 195-208.

[12] X. Zhou, J. Wang, J. Zhang, D.S. Jeng. Wave and current induced seabed response around a submarine pipeline in an anisotropic seabed. Ocean Engineering 75 (2014), pp. 112-127.

[13] H.Y. Zhao, D.S. Jeng, Z. Guo, J.S. Zhang. Two-dimensional model for pore pressure accumulations in the vicinity of a buried pipeline. Journal of Offshore Mechanics and Arctic Engineering, ASME 136(4) (2014), 042001.

[14] Z. Lin, Y. Guo, D.S. Jeng, C. Liao, N. Rey. An integrated numerical model for wave-soilpipeline interactions. Coastal Engineering 108 (2016), pp. 25-35.

[15] D.Z. Pan, L.Z. Wang, C.H. Pan. Experimental investigation on the wave-induced pore pressure around shallowly embedded pipelines. Haiyang Xuebao (in Chinese) 26(5) (2007), pp. 125-135.

[16] B.M. Sumer, J. Fredsøe, S, Christensen, M. T. Lind. Christensen et al. Sinking/floatation of pipelines and other objects in liquefied soil under waves. Coastal Engineering 38 (1999), pp. 53-90.

[17] B.M. Sumer, C. Truelsen, T. Sichmann, J. Fredsøe. Onset of scour below pipelines and selfburial. Coastal Engineering 42 (2001), pp. 313-335.

[18] B.M. Sumer, C. Truelsen, J. Fredsøe. Liquefaction around pipelines under waves. Waterway, Port, Coastal, and Ocean Engineering, ASCE 132(4) (2006), pp. 266-275.

[19] C. Zhou, G. Li, P. Dong, J. Shi, J. Xu. An experimental study of seabed responses around a marine pipeline under wave and current conditions. Ocean Engineering 38 (2011), pp. 226234. 
[20] L.P. Yang, Y.K. Guo, B. Shi, C.P. Kuang, W.L. Xu, S.Y. Cao. Study of scour around submarine pipeline with a rubber plate or rigid spoiler in wave conditions. Journal of Waterways, Port, Coast and Ocean Engineering, ASCE 138 (2012), pp. 484-490.

[21] L.P. Yang, B. Shi, Y.K. Guo, X.Y. Wen. Calculation and experiment on scour depth for submarine pipeline with a spoiler. Ocean Engineering 55 (2012), pp. 191-198.

[22] L.P. Yang, B. Shi, Y.K. Guo, L.X. Zhang, J.S. Zhang, Y. Han. Scour protection of submarine pipelines using rubber plates underneath the pipes. Ocean Engineering 84 (2014), pp. 176182.

[23] J Fredsøe, Pipeline-Seabed Interaction. Journal of Waterway, Port, Coastal and Ocean Engineering, ASCE 142(6) (2016), 03116002.

[24] A. Hettler. Gründungskörper mit zyklischer Belastung in Sand und 1g-Modelltechnik. Bautechnik 77(12) (2000), pp. 901-908.

[25] B. Lé Mehauté. An introduction to hydrodynamics and water waves. Heidelberg, Berlin: Springer (1976), pp. 315.

[26] S.Y. Tzang. Water wave-induced soil fluidization in a cohesionless fine-grained seabed. PhD Thesis, University of California-Berkeley, Berkeley, CA (1992).

[27] J.S. Zhang, D.S. Jeng, P.L.F. Liu. Numerical study for waves propagating over a porous seabed around a submerged permeable breakwater: PORO-WSSI II model. Ocean Engineering 38(7) (2011), pp. 954-966.

[28] P. Lin, P.L.F. Liu. Internal wave-maker for Navier-Stokes equations models. Journal of Waterway, Port, Coastal, and Ocean Engineering, ASCE 125(4) (1999), pp. 207-215.

[29] M.A. Biot. General theory of three-dimensional consolidation. Journal of Applied Physics 12 (1941), pp. 155-164.

[30] A Veruijt. Elastic storage of aquifer, In: Flow Through Porous Media, edited by De Wiest, R. J. M., Academic Press, New York, 1969, pp. 331-376.

[31] D. Pan, L. Wang, C. Pan, J. Hu. Experimental investigation on the wave-induced pore pressure around shallowly embedded pipelines. Acta Oceanologica Sinica 26(5) (2007), pp. 125-135.

[32] S.C. Chang, J.G. Lin, L.K. Chien et al. An experimental study on non-linear progressive wave-induced dynamic stresses in seabed. Ocean Engineering 34 (2007), pp. 2311-2329.

[33] T. Yamamoto, H.L. Koning, H. Sellmeijer, E. van Hijum. On the response of a poro-elastic bed to water waves. Journal of Fluid Mechanics 87 (2) (1978), pp. 193-206.

[34] T.L. Lee, C.P. Tsai, D.S. Jeng. Ocean waves propagating over a porous seabed of finite thickness. Ocean Engineering 29 (12) (2002), pp. 1577-1601.

[35] S.Y. Tzang, S.H. Ou. Laboratory flume studies on monochromatic wave-fine sandy bed interactions Part 1: soil fluidization. Coastal Engineering 53 (11) (2006), pp. 965-982.

[36] A.C. Palmer, R.A. King. Subsea Pipeline Engineering. second ed. PennWell Books, Tulsa, Oklahoma (2008). 
[37] H.Y. Zhao, D.S. Jeng. Numerical study for wave-induced pore pressure accumulations around buried pipeline: Effects of back-filled trench layer. The 14th International Conference of the International Association for Computer Methods and Advances in Geomechanics (14IACMAG), Kyoto, Japan, September 22-25 (2014), pp. 1113-1118.

[38] H.Y. Zhao, D.S. Jeng. Accumulated pore pressures around submarine pipeline buried in trench layer with partial backfills. Journal of Engineering Mechanics, ASCE 142 (7) (2016), 04016042.

[39] J.S. Zhang, Q. Li, C. Ding, J.H. Zheng, T.T. Zhang. Experimental investigation of wavedriven pore-water pressure and wave attenuation in a sandy seabed. Advances in Mechanical Engineering 8(6) (2016), 1687814016651207.

[40] D.S. Jeng. Numerical modeling for wave-seabed-pipe interaction in a non-homogeneous porous seabed. Soil Dynamics and Earthquake Engineering, 21(8) (2001), pp. 699-712.

[41] N. Tisato, B. Quintal. Laboratory measurements of seismic attenuation in sandstone: strain versus fluid saturation effects. Geophysics 79 (2014), pp. WB9-WB14. 